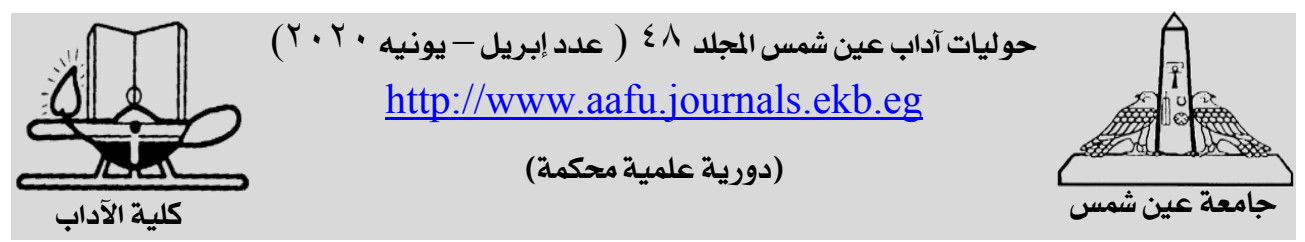

\title{
ارجاء المعنى وبنتاء الصورة المسرحية في العرض المسرحي المرجع والاليات والاشتغال
}

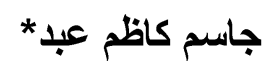

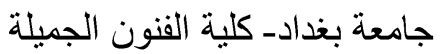

يسعى التقويض الى استبعاد الثابت اليقيني، بو اسطة عملية الارجاء التي يجرئياء

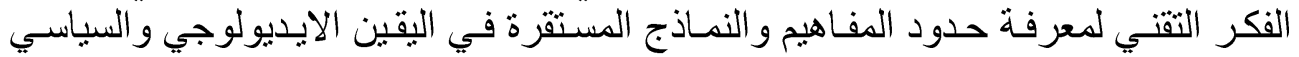

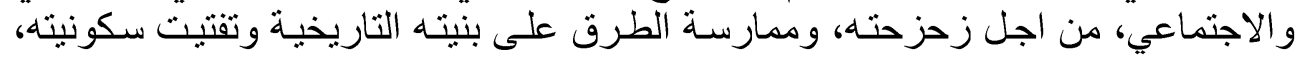

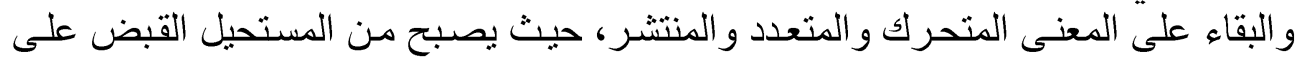

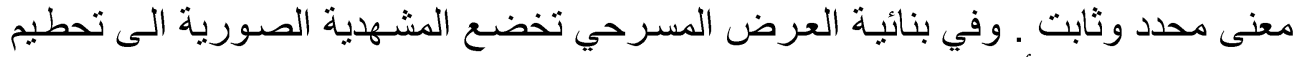

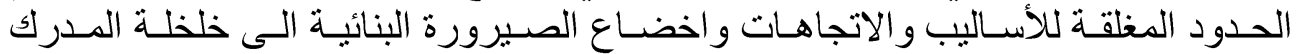

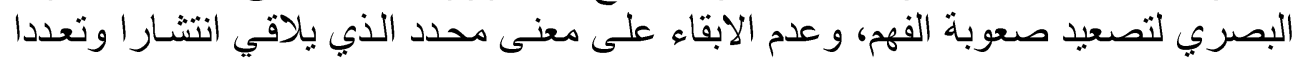

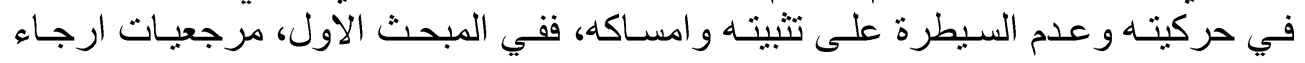

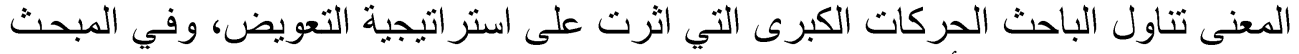

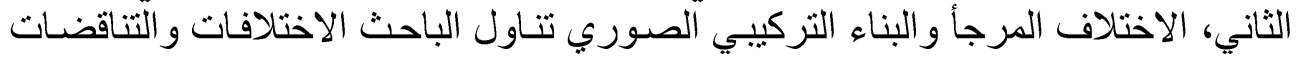

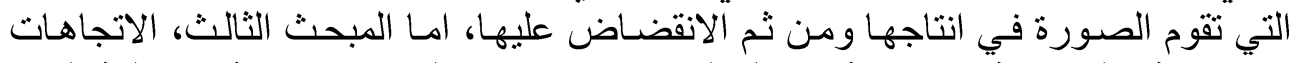

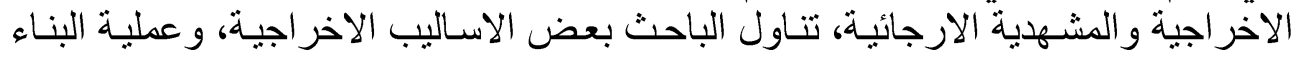

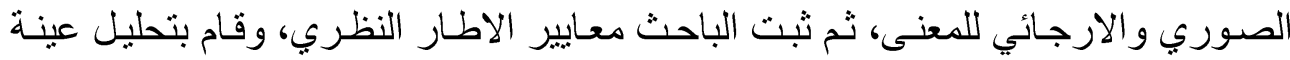

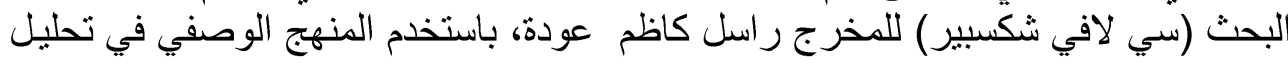

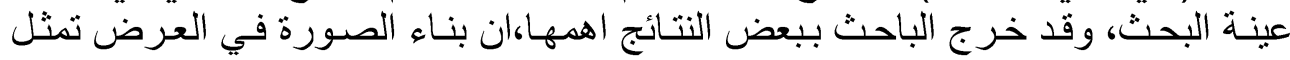

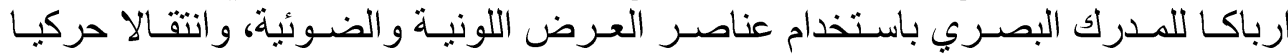

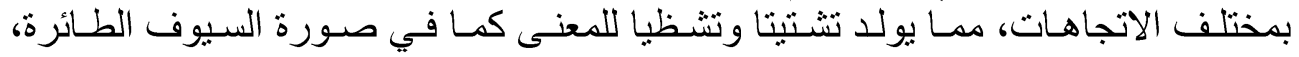

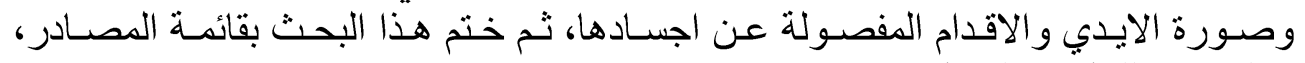

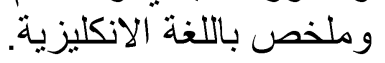




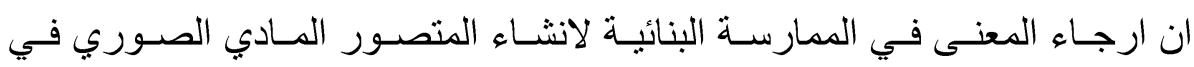

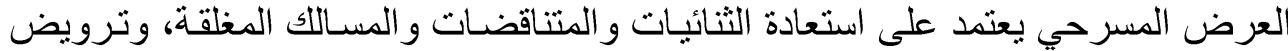

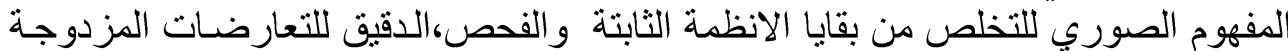

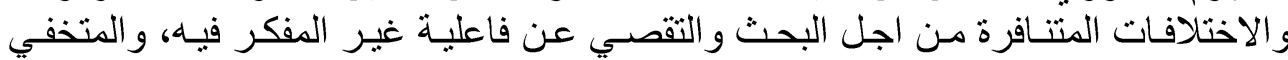

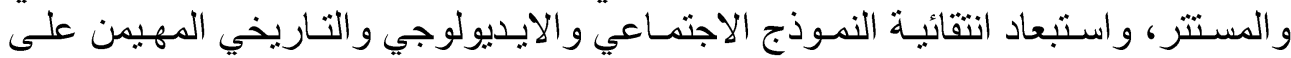

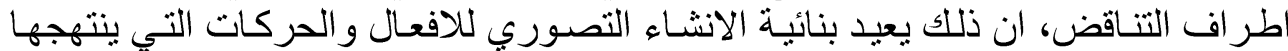

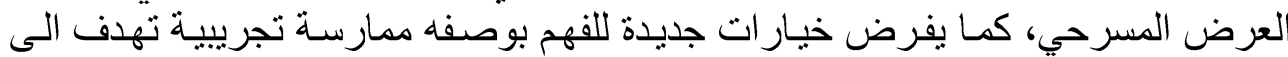

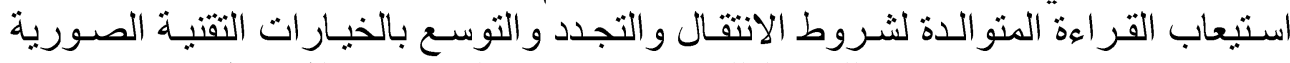

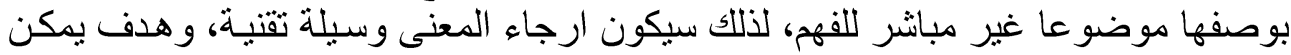

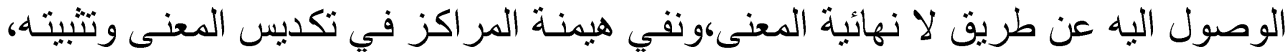

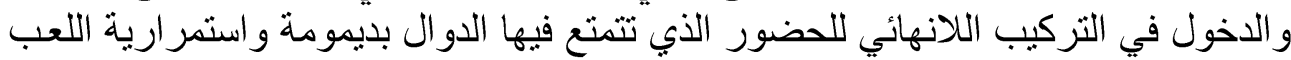

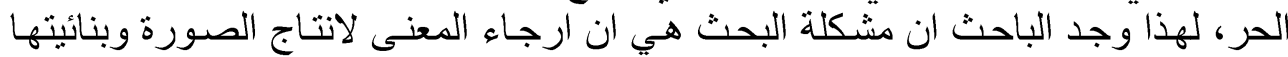

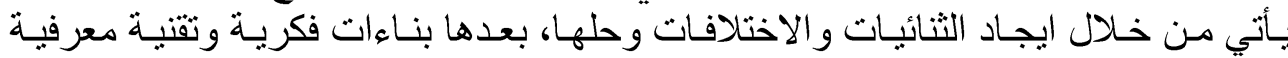

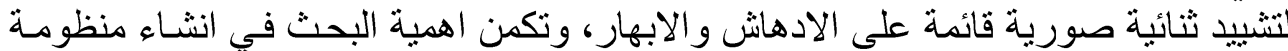

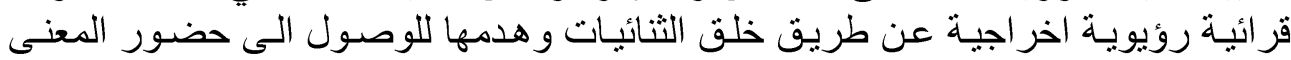

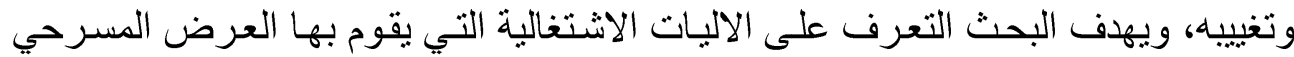

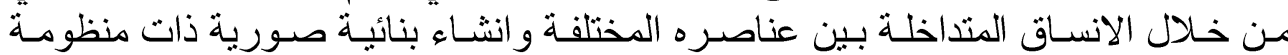

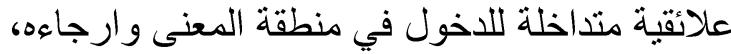

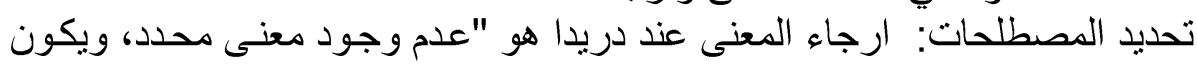

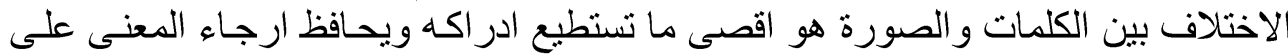

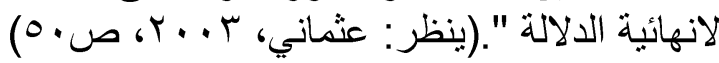

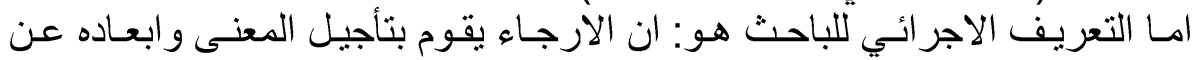

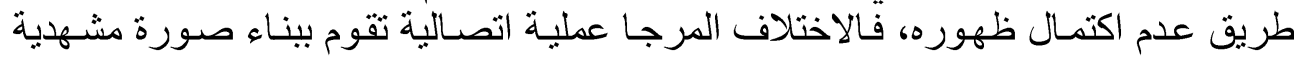

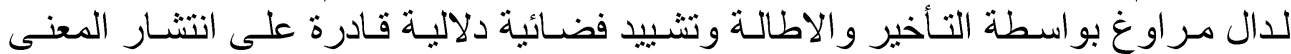

\section{المبحث الاول:- مرجعيات ارجاء المعنى}

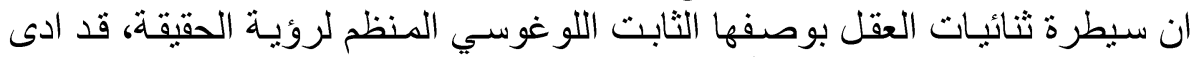

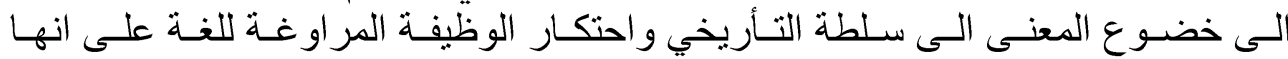

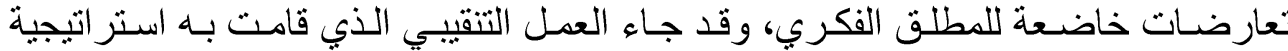
التفكيك في فحص النصوص قد اوجد ان التعارضات وات والثنائيات ماهي الا اوهام اللغة، و وعن

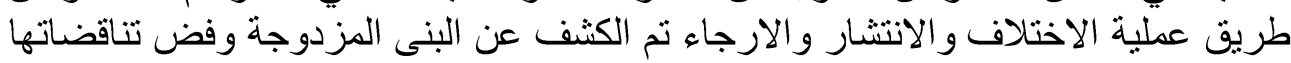

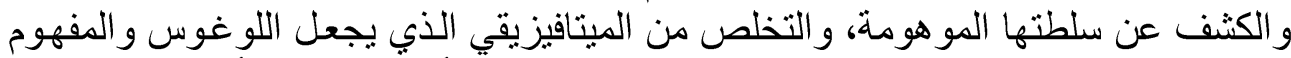

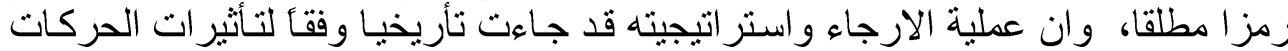

الكبرى الرومانتيكية، الماركسية، فرويد، النيتشويةــ الظاهر اتية.

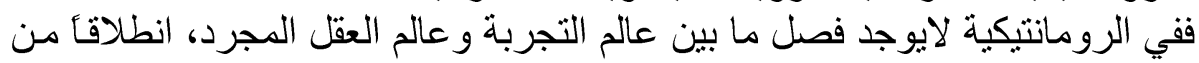

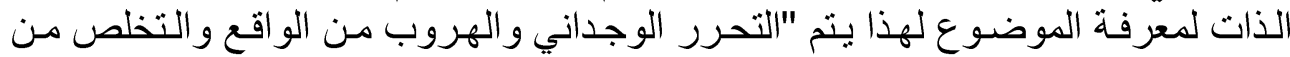




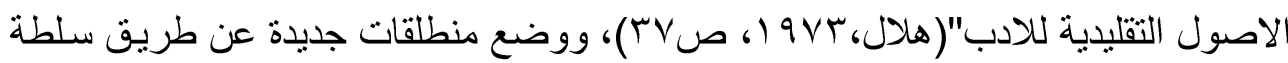

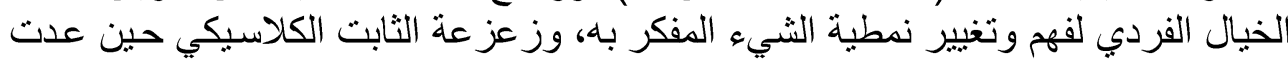

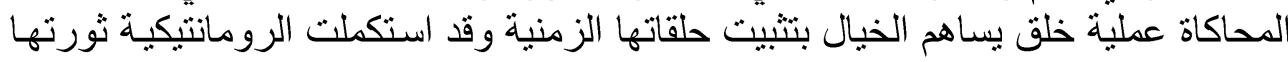

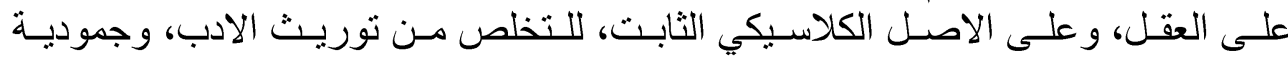

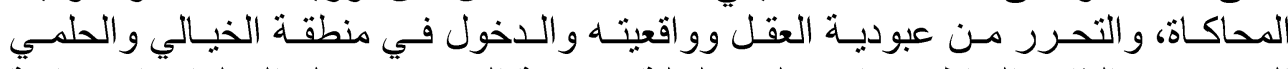

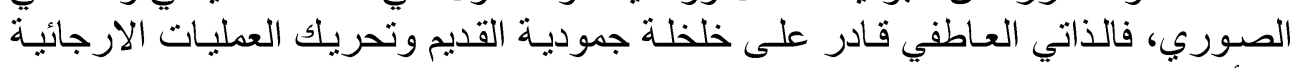

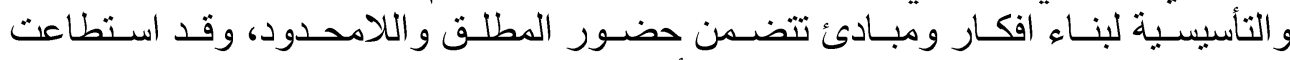

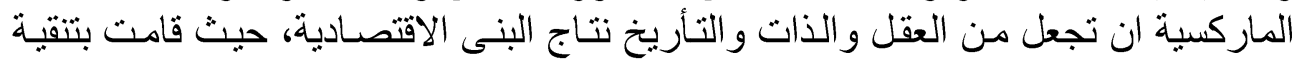

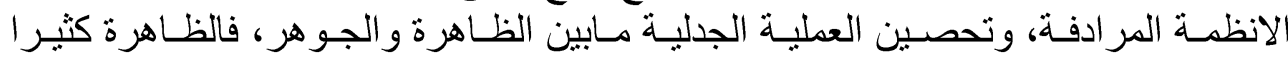

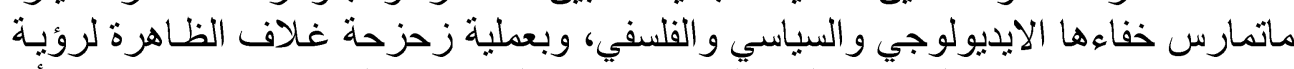

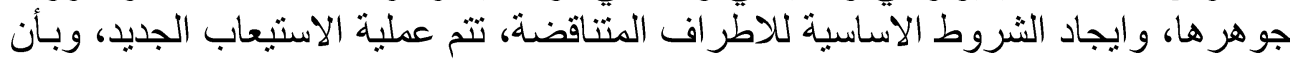

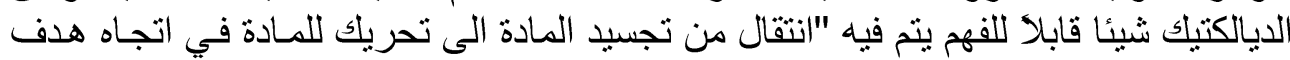

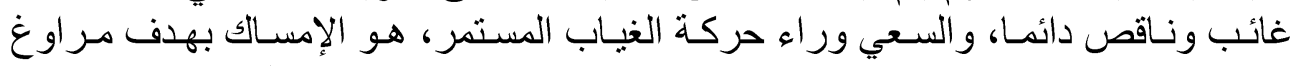

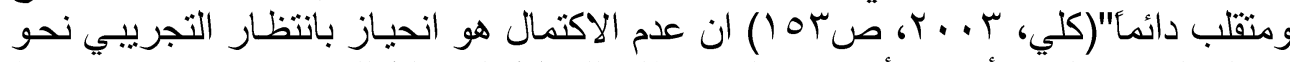

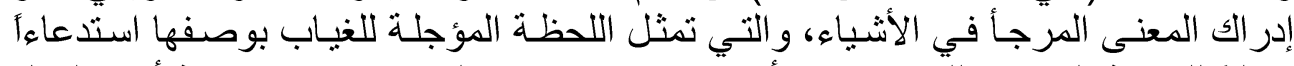

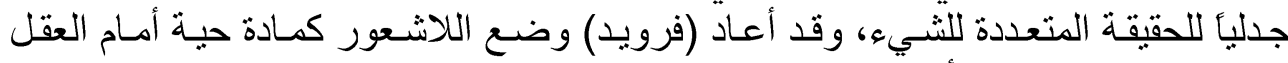

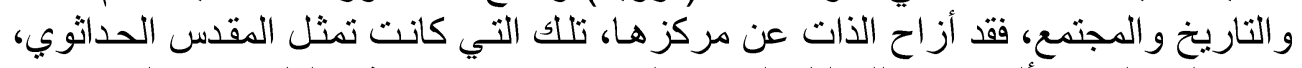

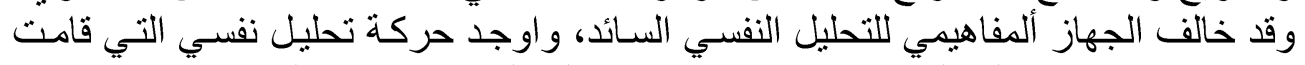

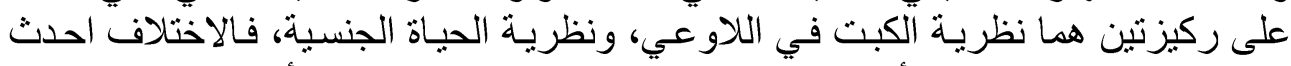

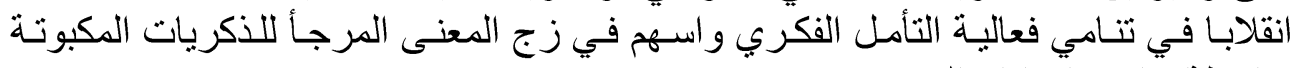

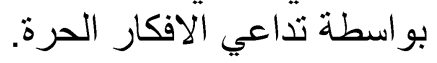

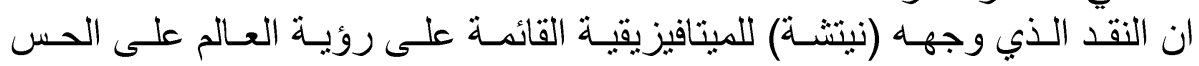

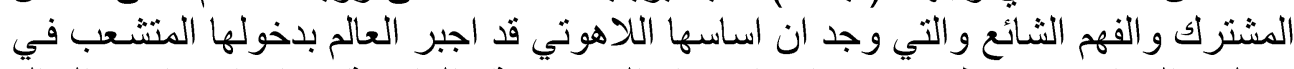

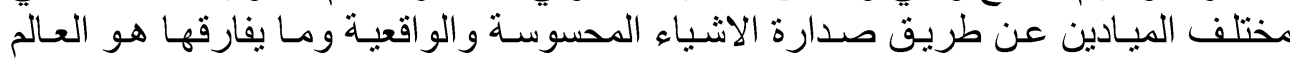

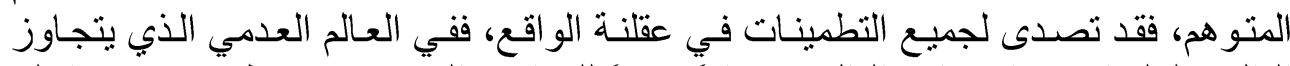

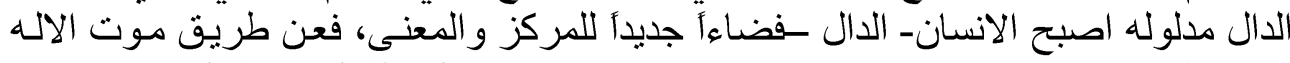

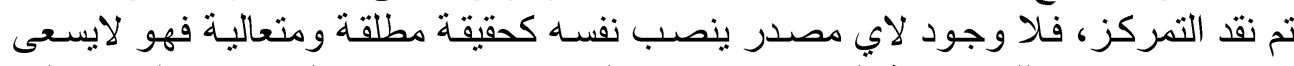

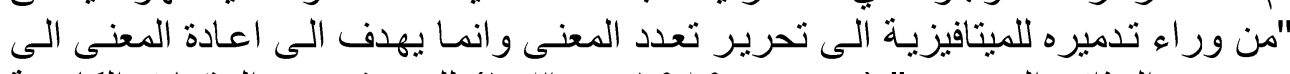

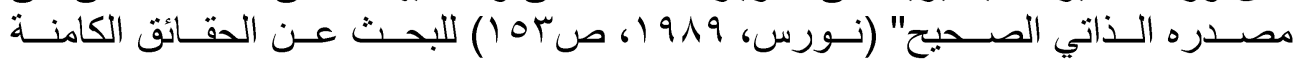

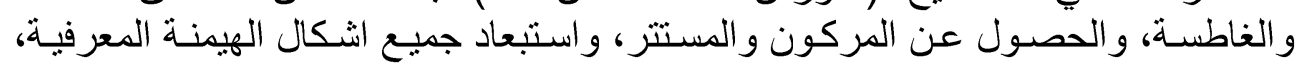

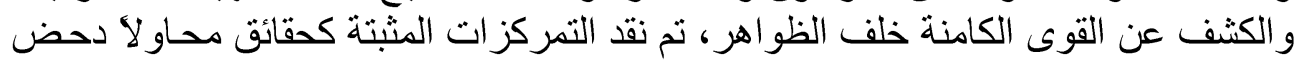

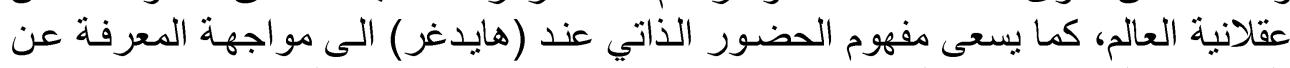

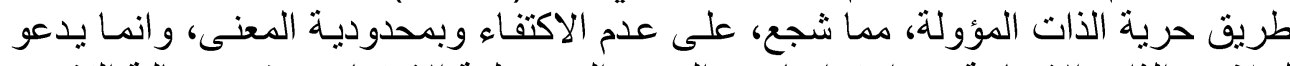

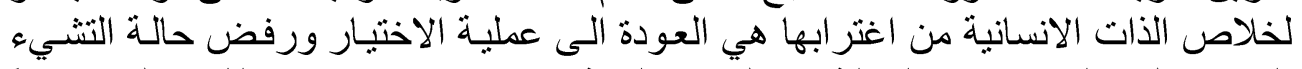

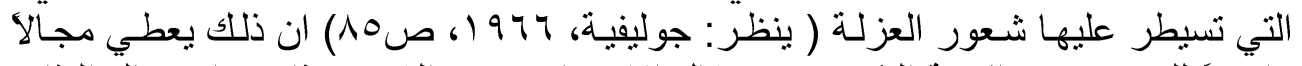

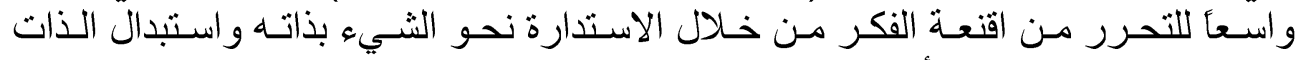

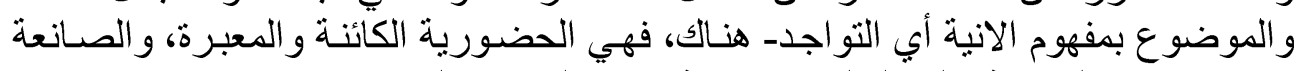

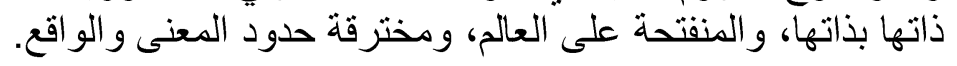


المبحث الثاني: الاختلاف المرجأ والبناء التركيبي الصوري التروياء

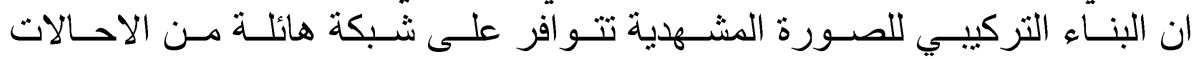

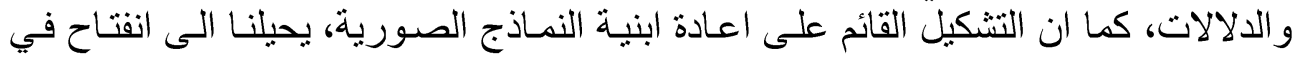

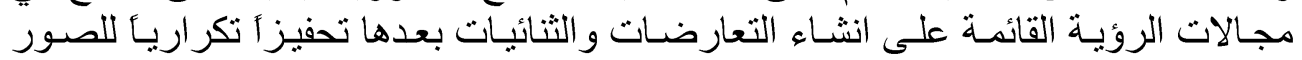

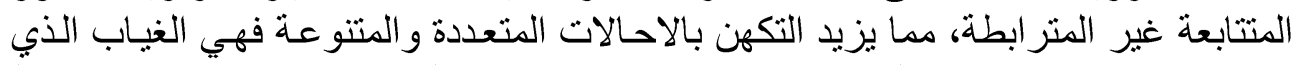

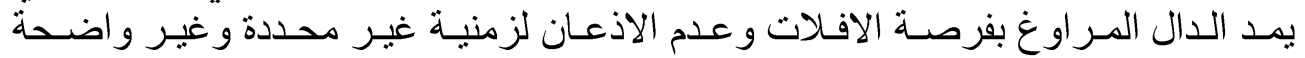

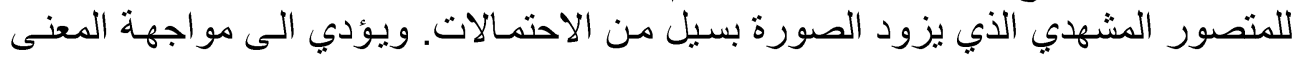

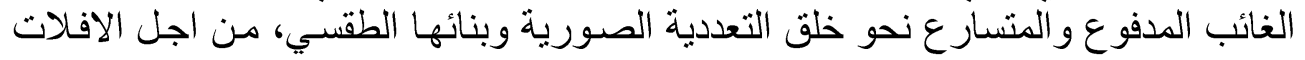

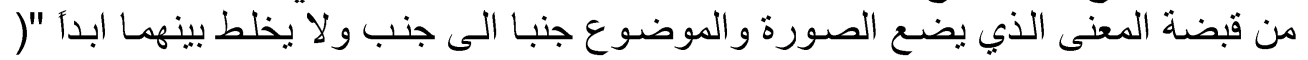

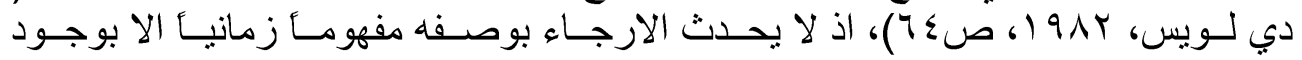

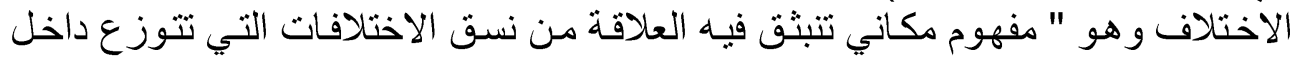

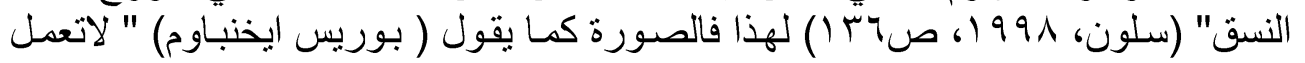

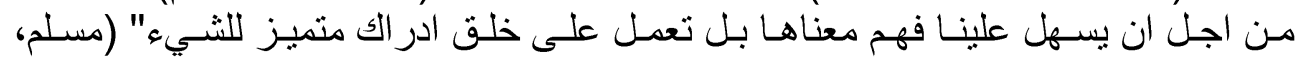

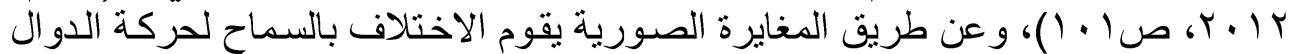

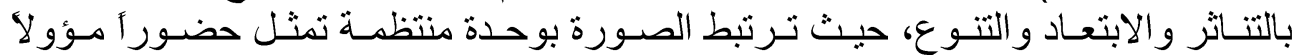

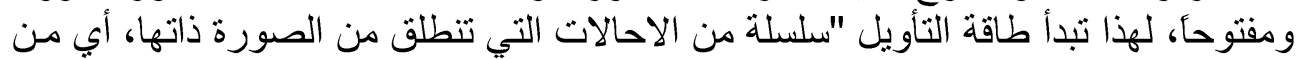

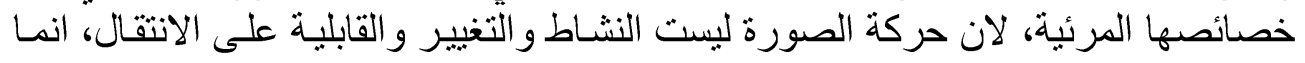

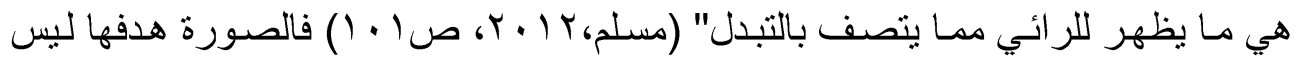

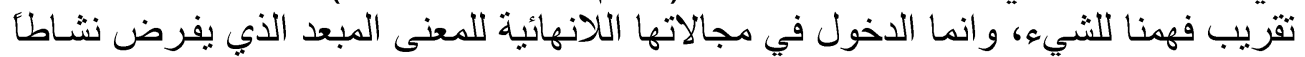

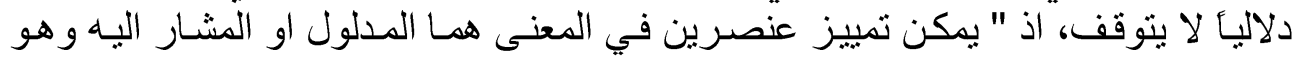

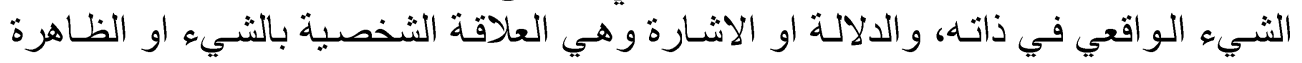

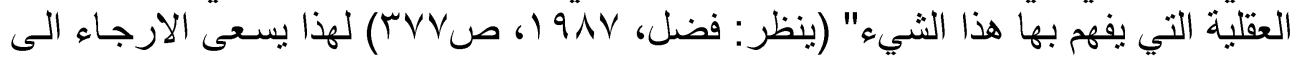

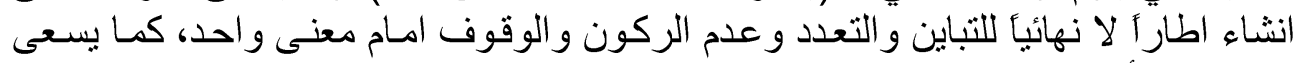

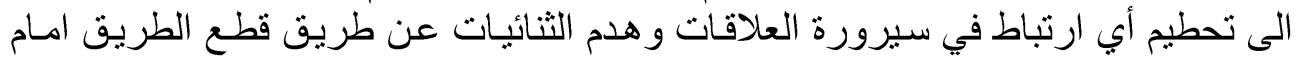

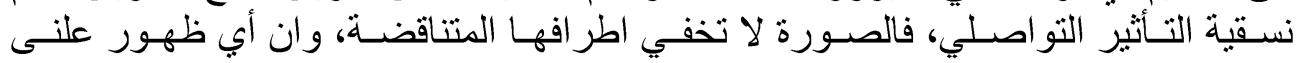

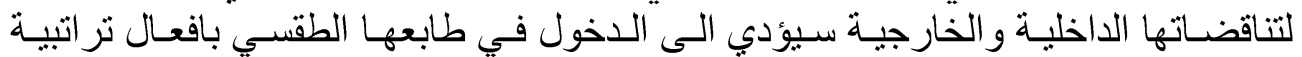

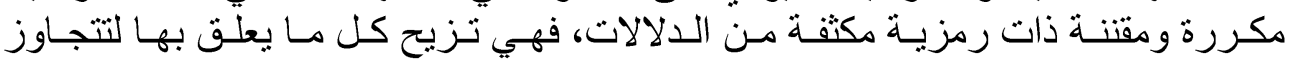

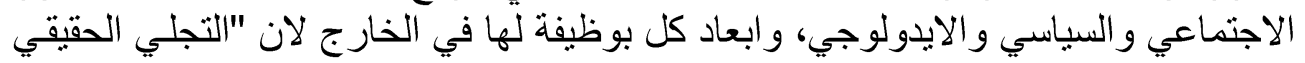

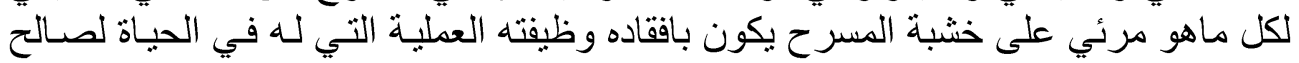

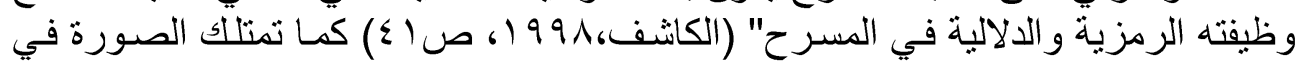

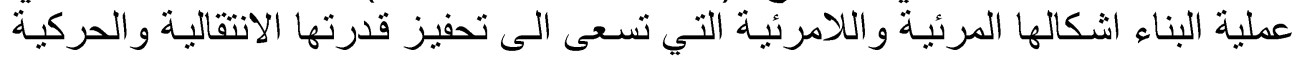

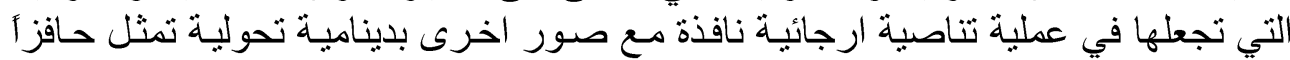

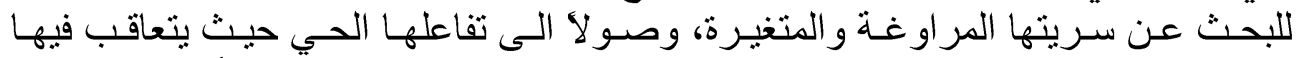

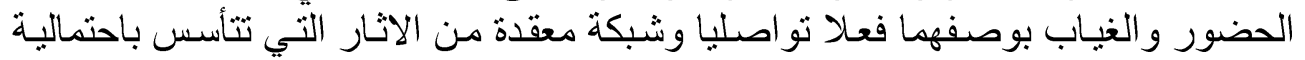

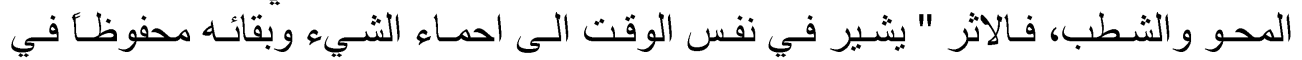

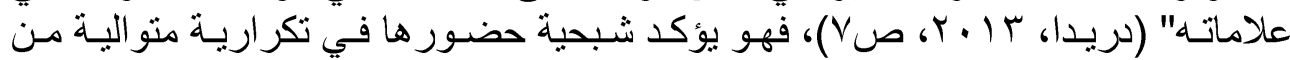

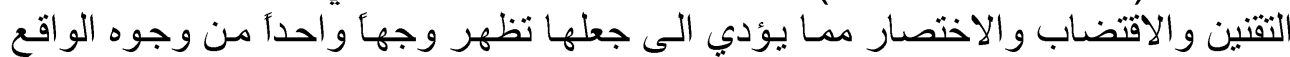

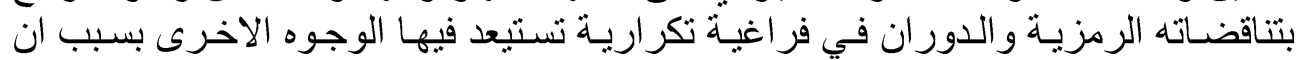




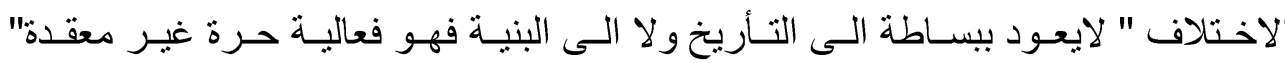

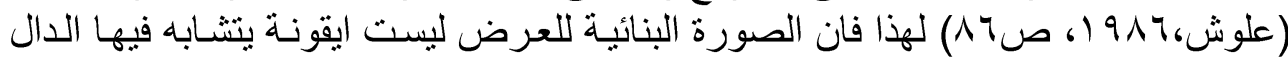

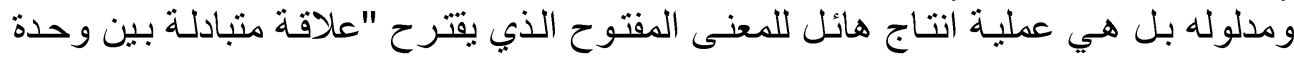

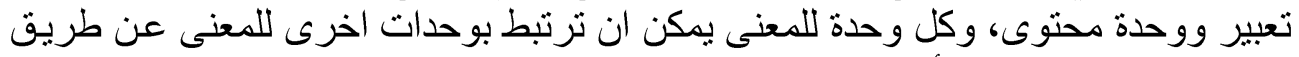

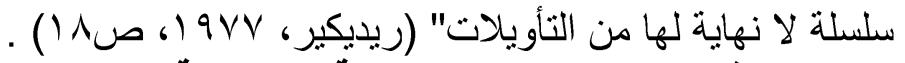

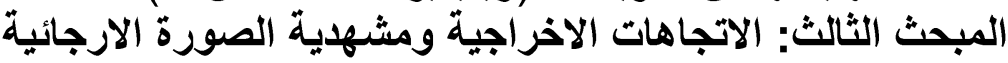

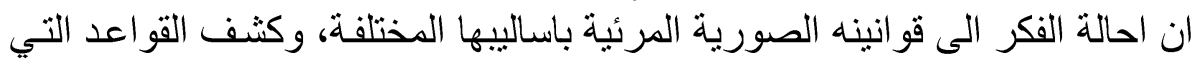

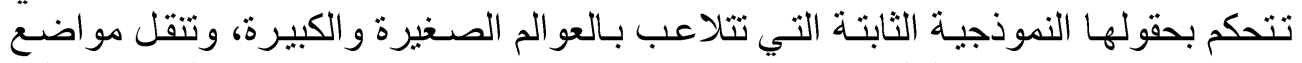

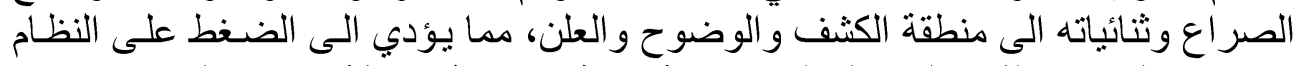

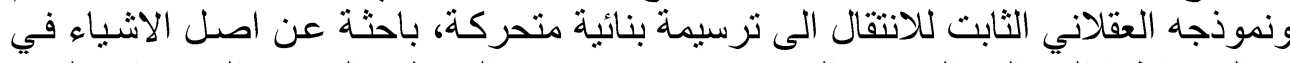

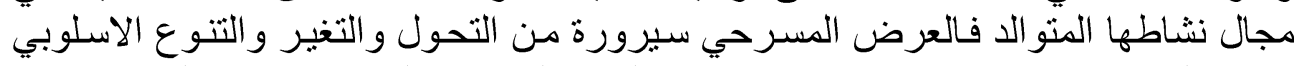

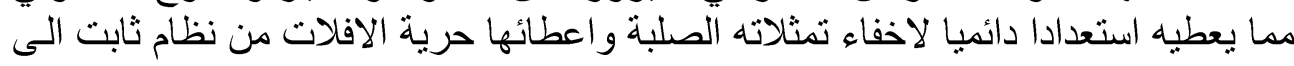

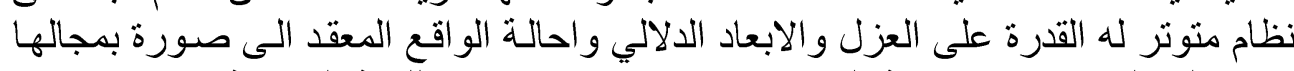

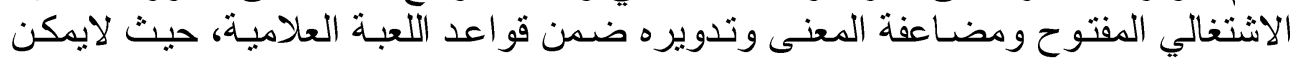

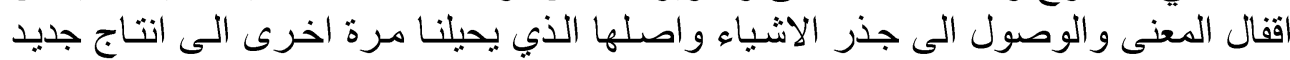

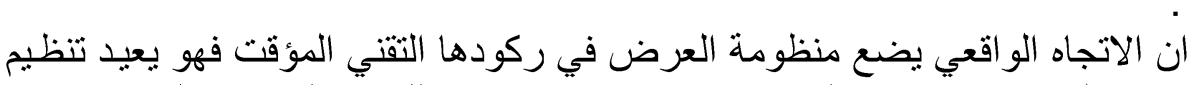

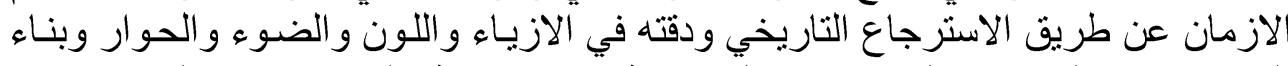

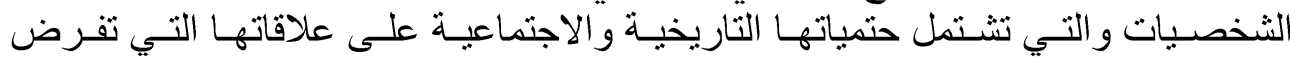

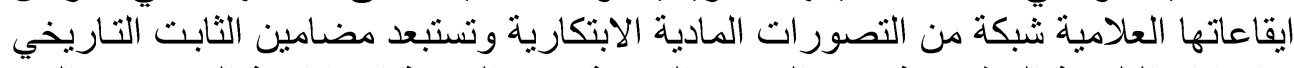

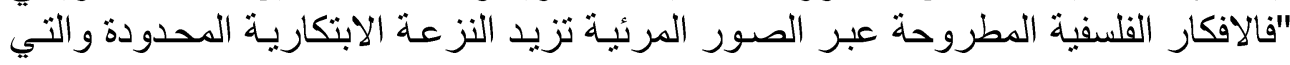

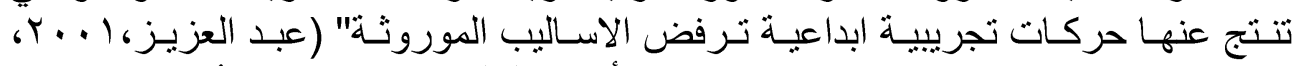

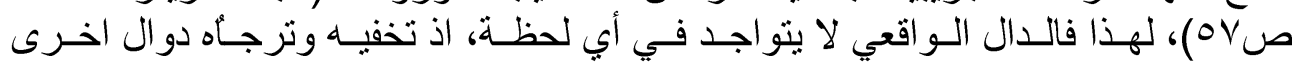

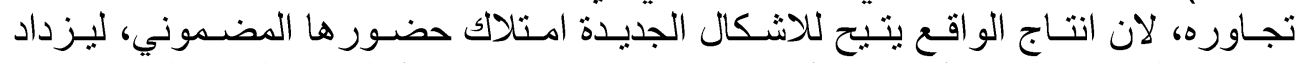

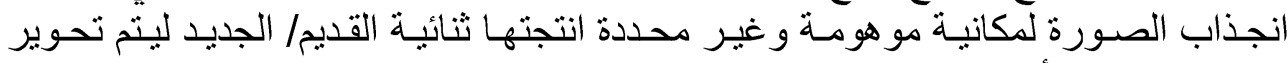

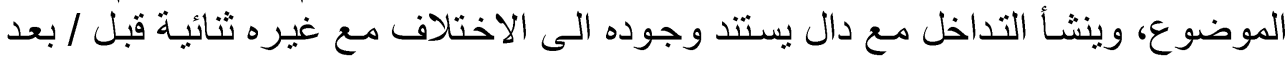

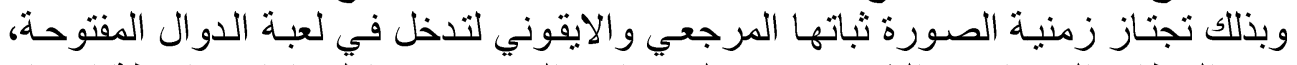

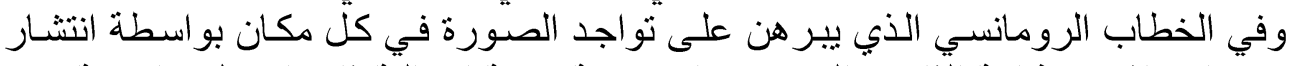

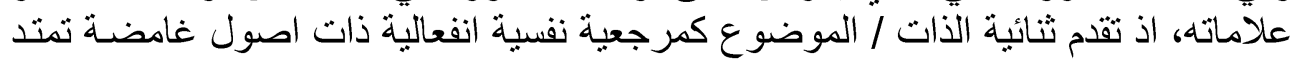

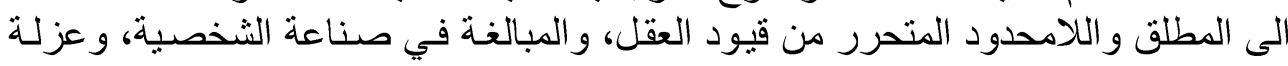

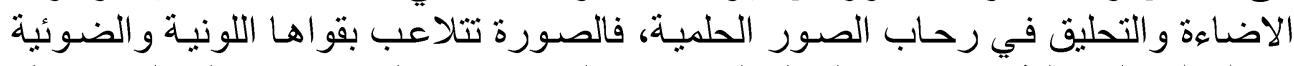

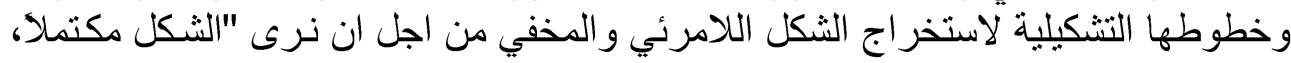

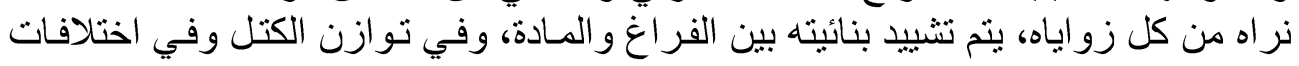

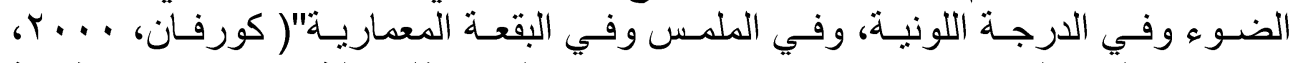

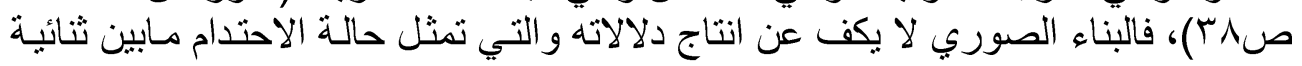

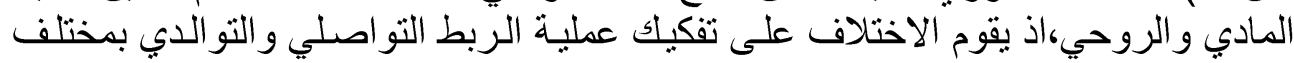

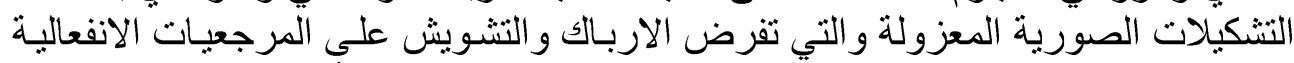

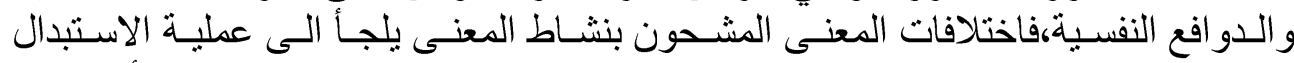

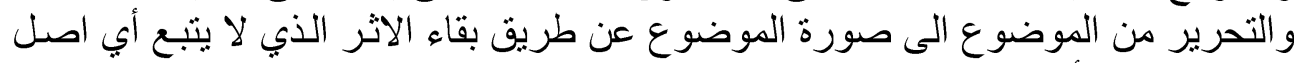

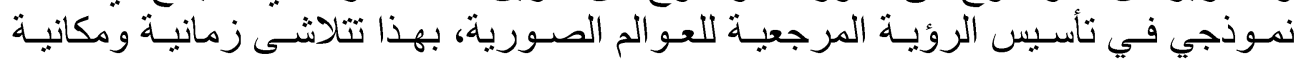




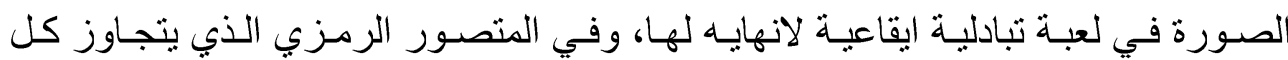

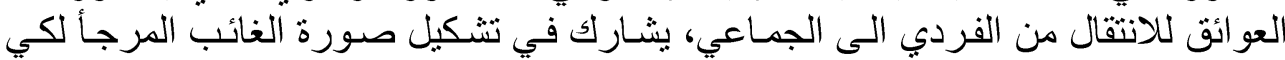

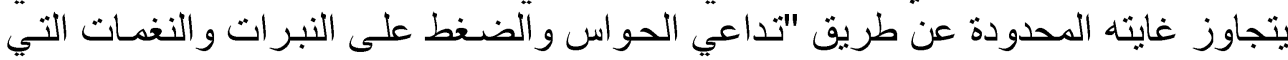

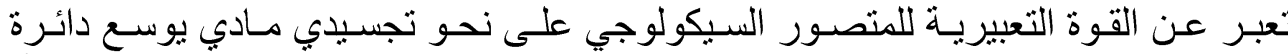

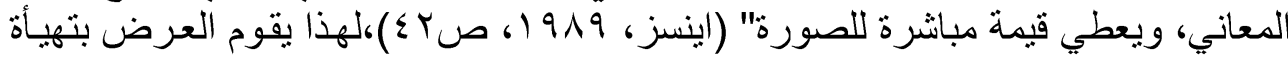

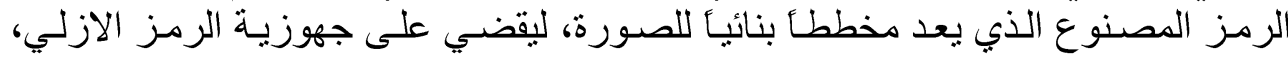

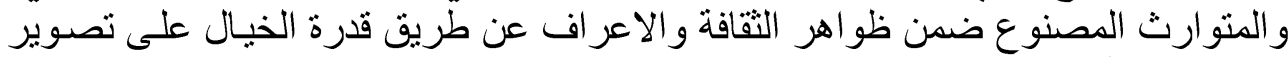

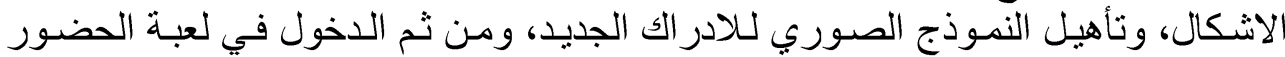

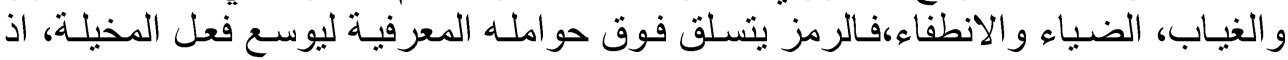

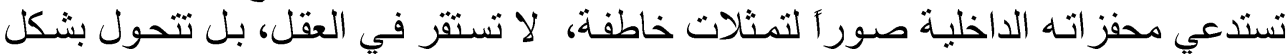

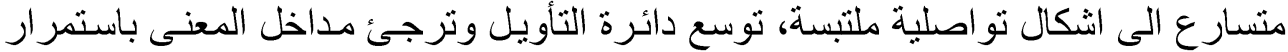

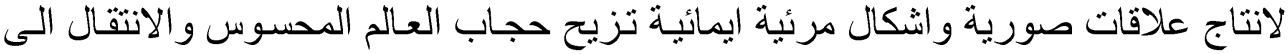

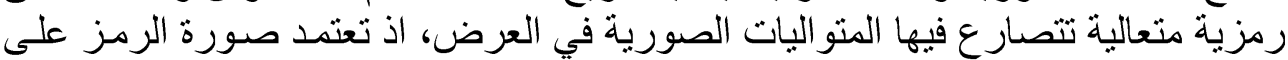

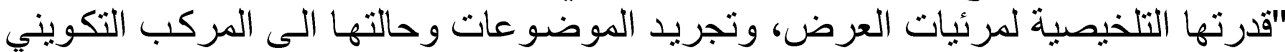

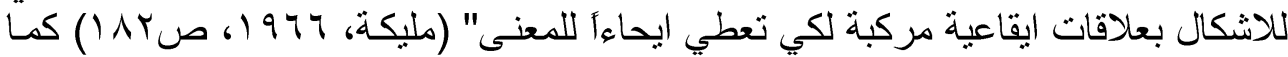

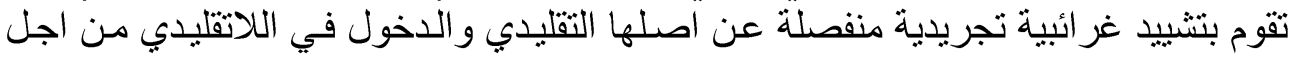

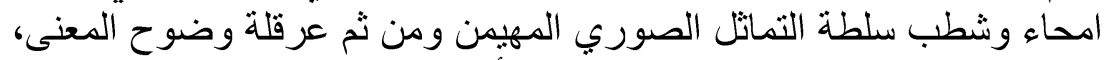

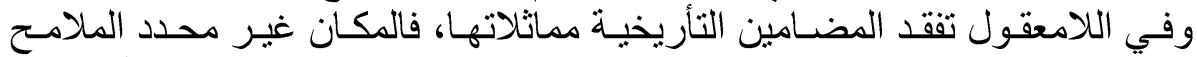

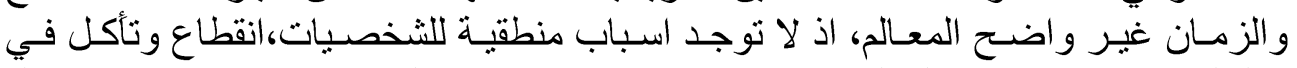

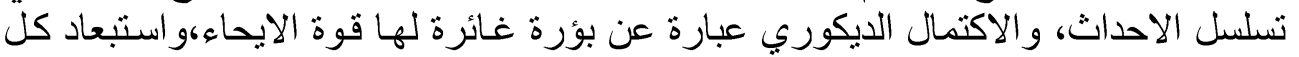

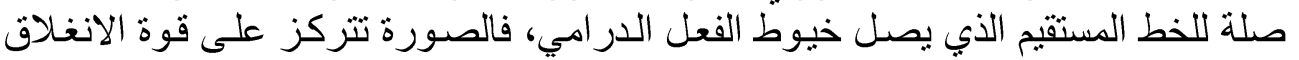

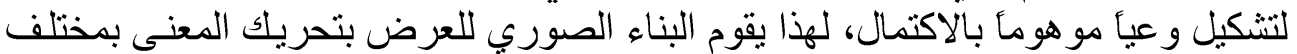

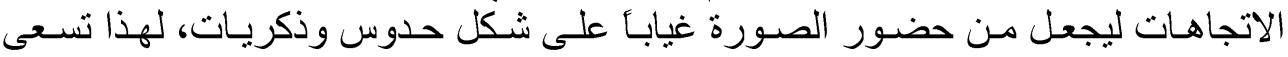

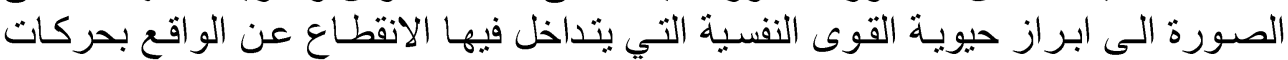

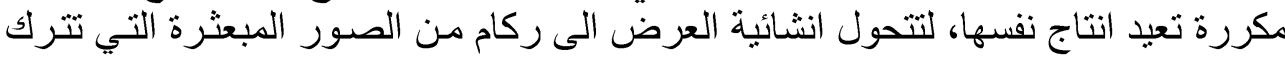

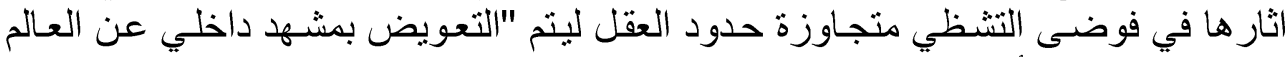

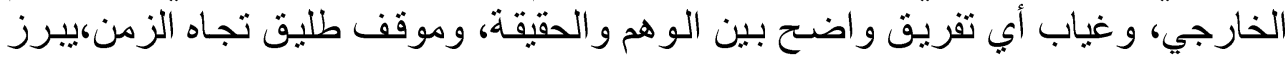

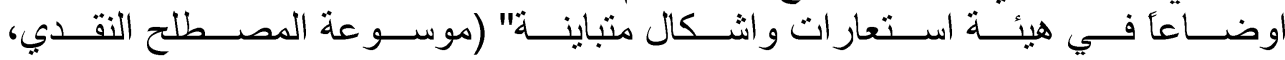

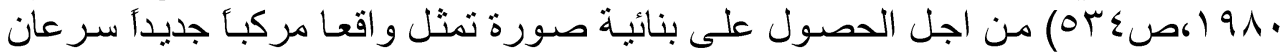

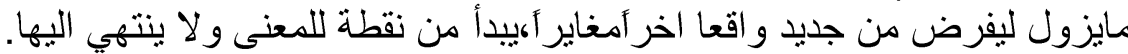

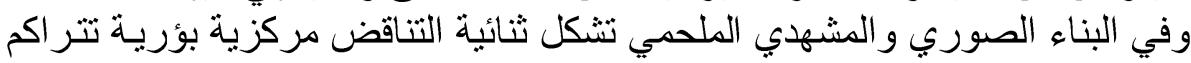

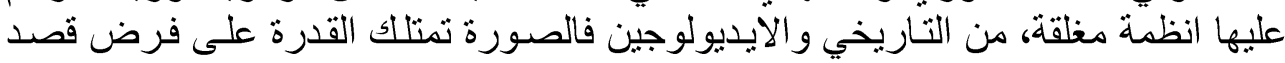

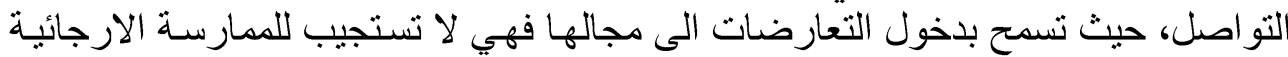

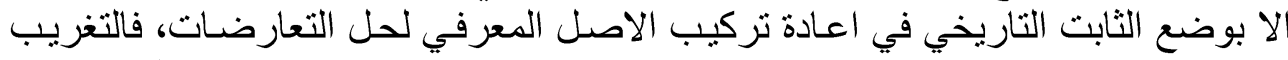

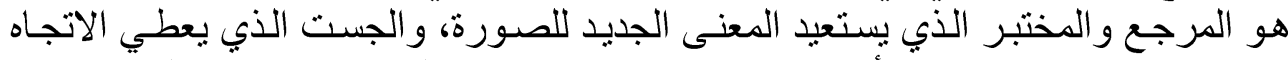

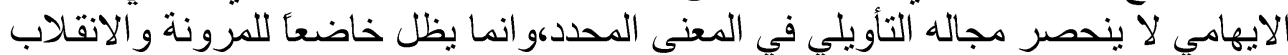

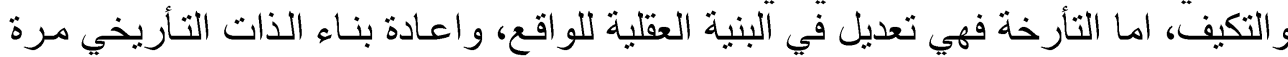

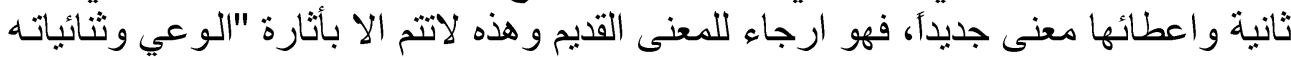

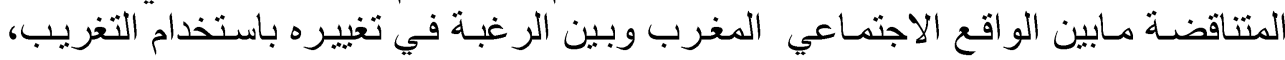




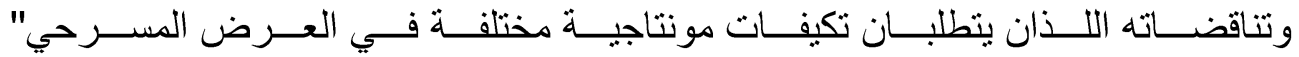

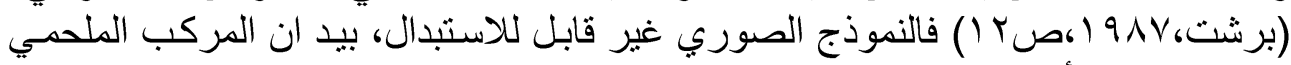

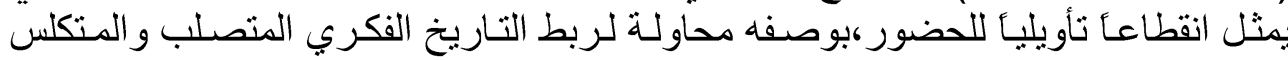

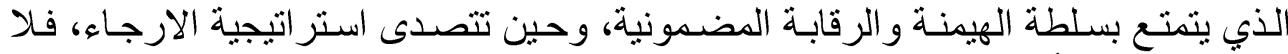

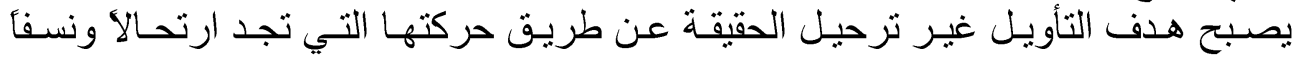

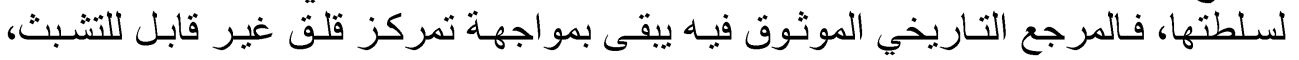

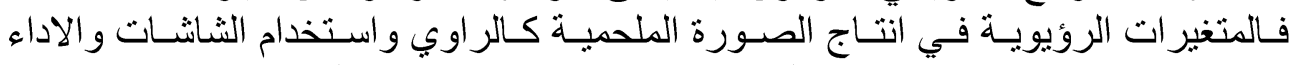

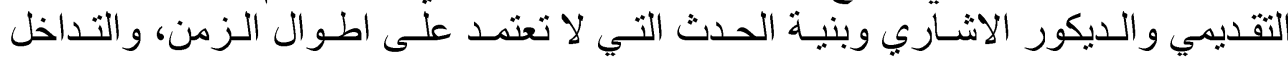

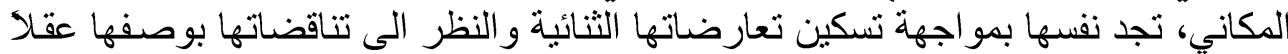

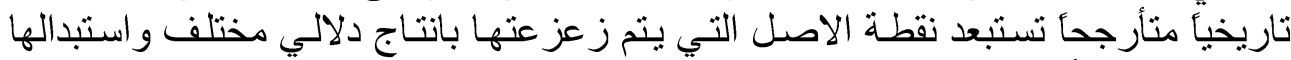
بمرجع حركي أخر. ما اسفر عنه الاطار النظري أخري

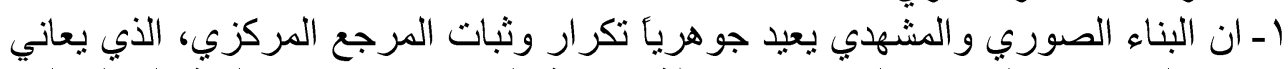

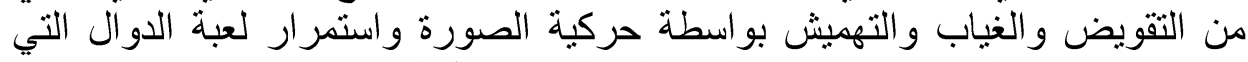

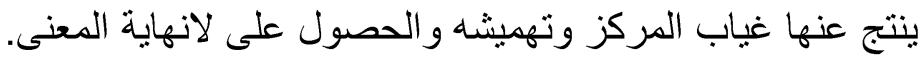

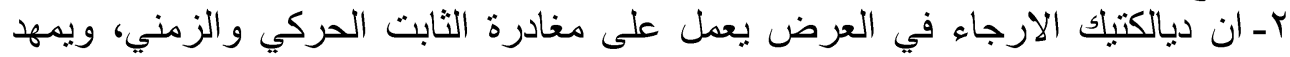

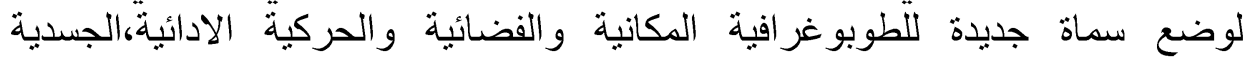

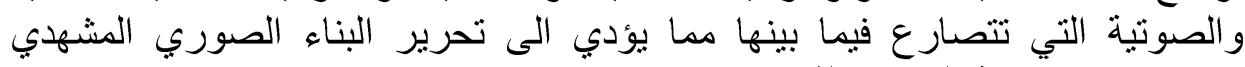
وتلاشي خصوصية المرجع الثابت.

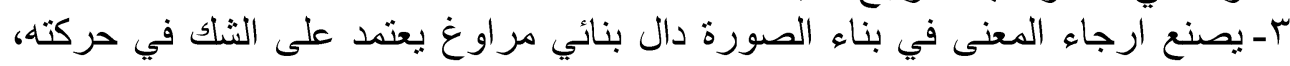

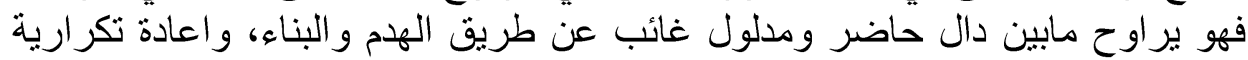

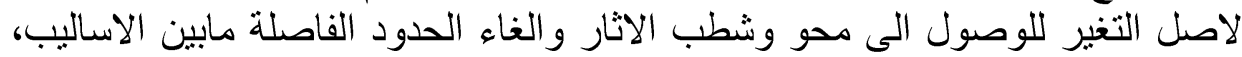

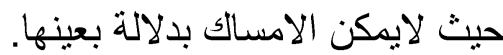

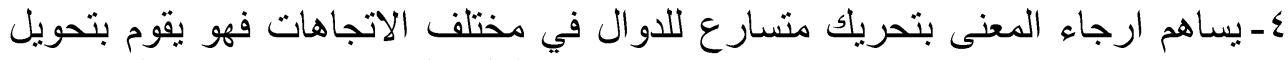

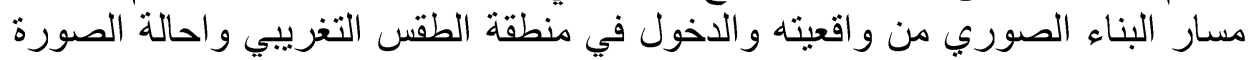

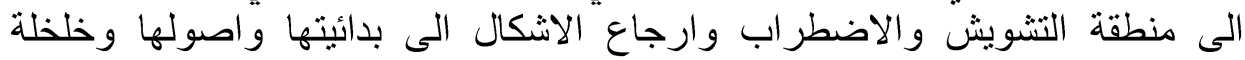

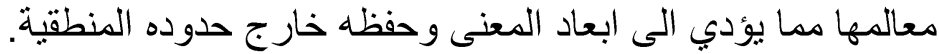

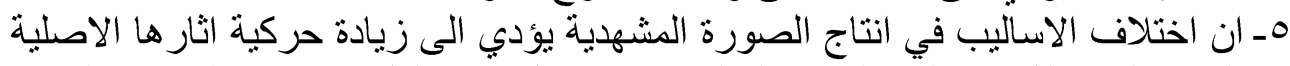

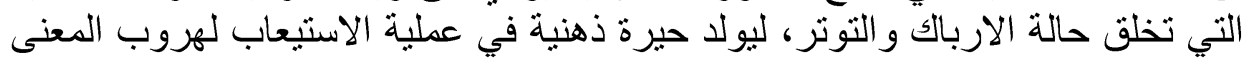

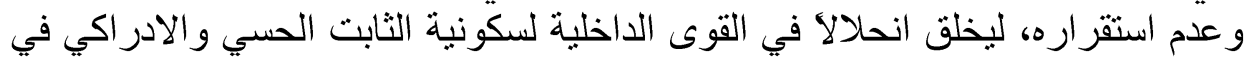

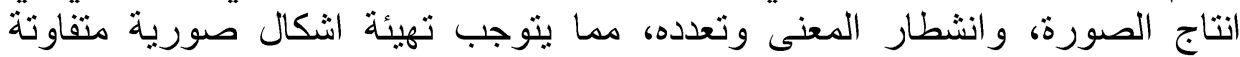
ومتنو عة ومتحولة لعرقلة عملية الفهر. 


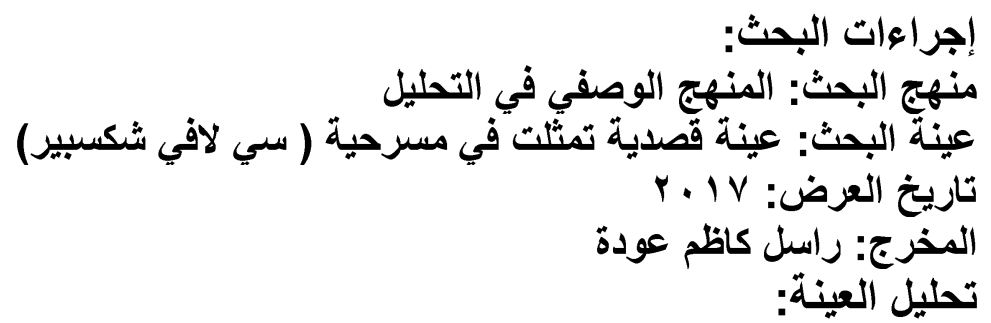

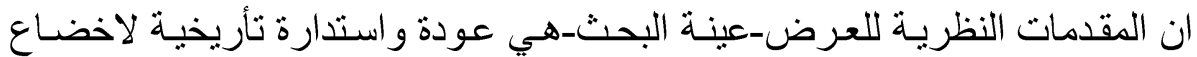

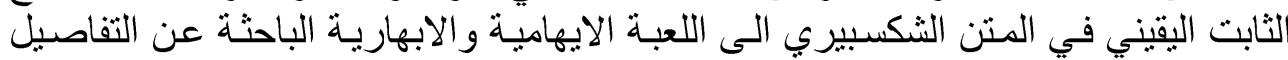

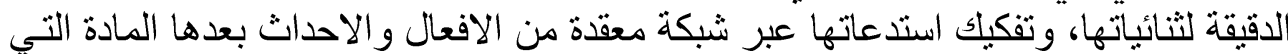

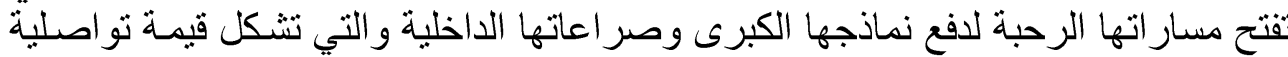

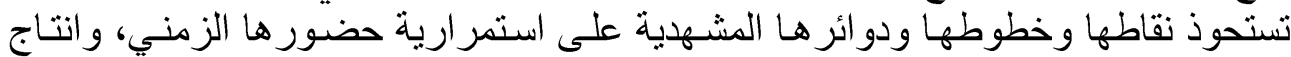

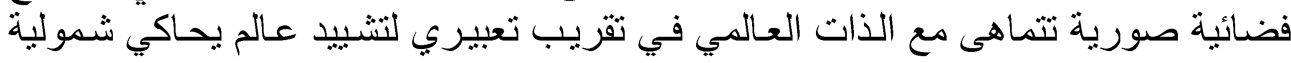

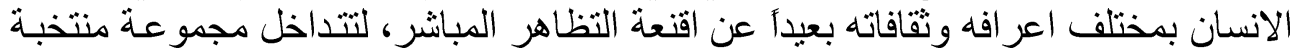

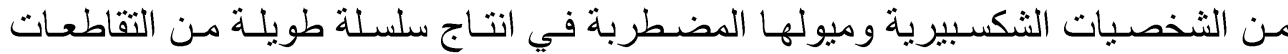

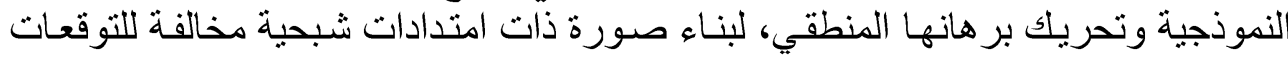

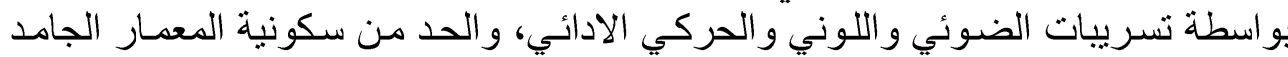

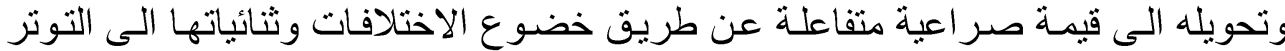

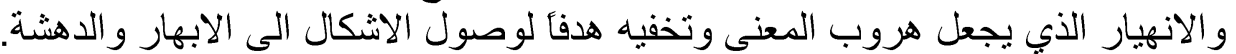

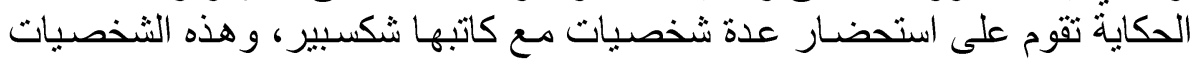

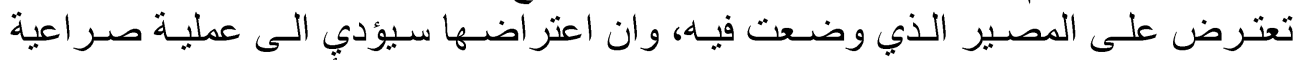

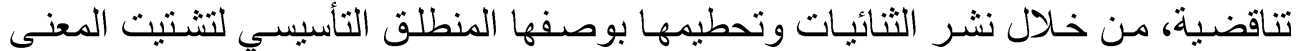
و انتشاره.

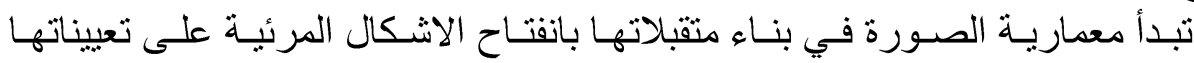
المتخيلة لتقسيم المساحة الفر اغية للعرض فيلة فبر خطوطها التعبيرية المستقيمة منها و الدائريـة،

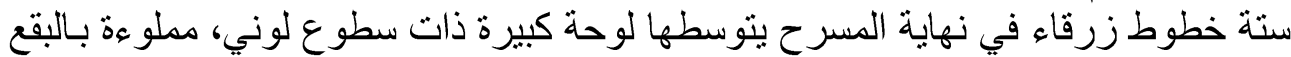

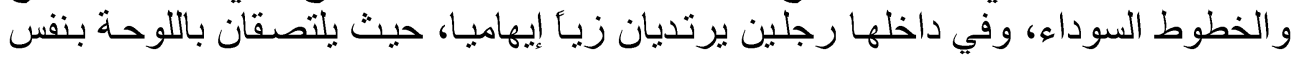

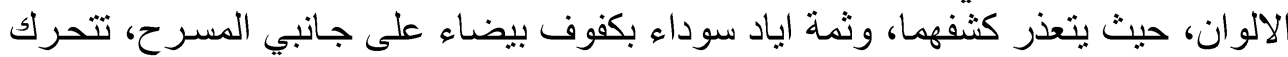

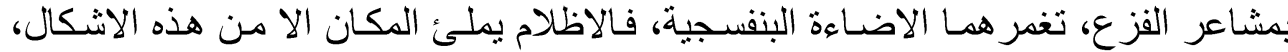

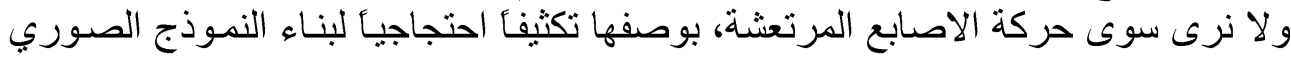

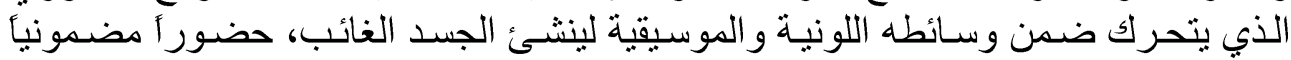

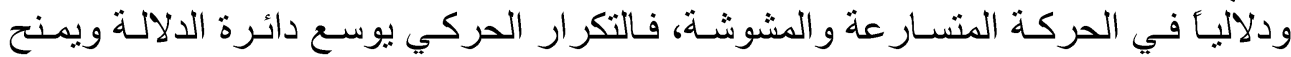

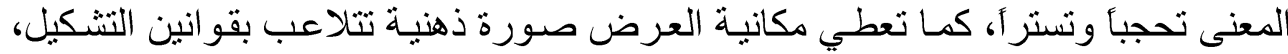

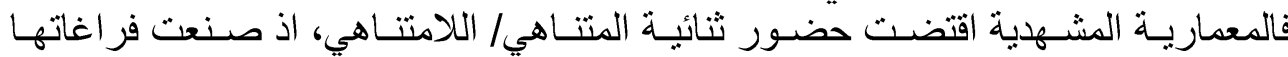

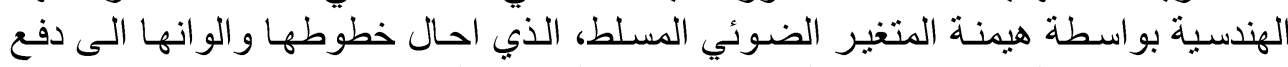
تصور اتها لمعايشة نماذجها الادائية، وحقةت ملته ملائمة صورية الطية بينهما.

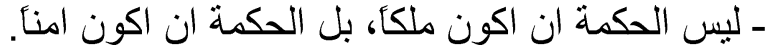

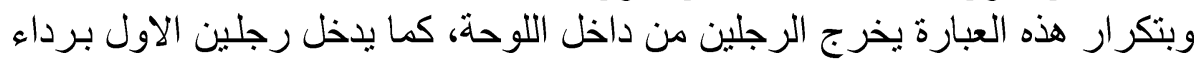

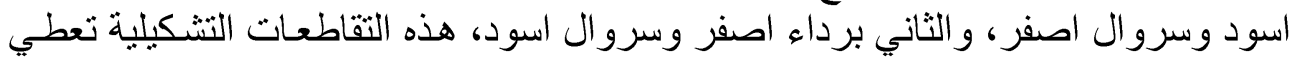




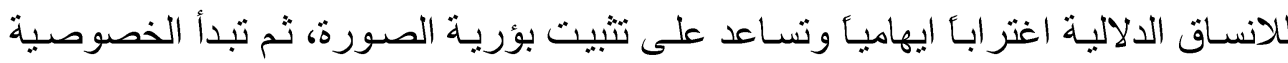

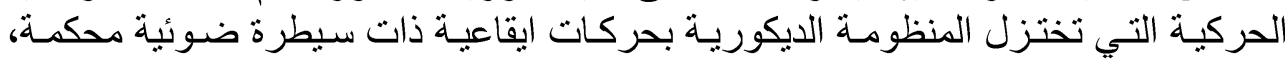

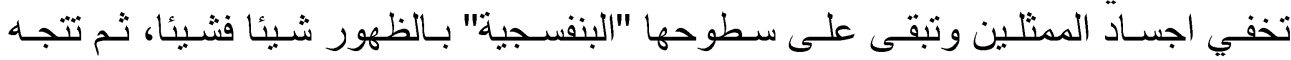

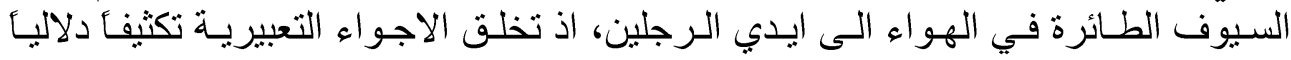

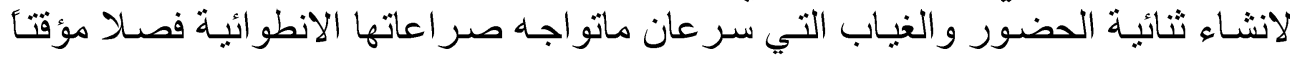

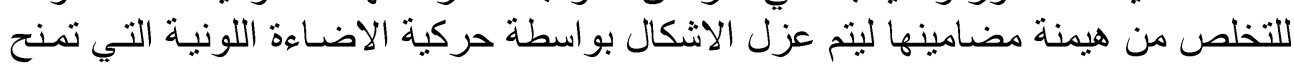

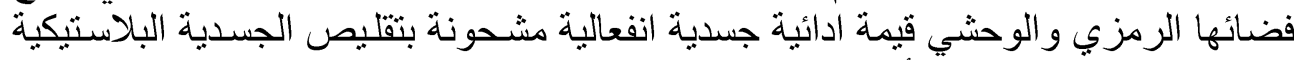

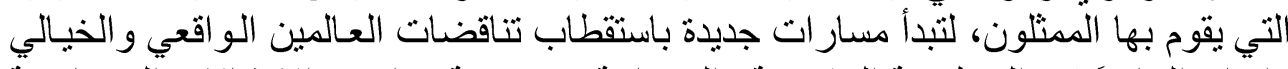

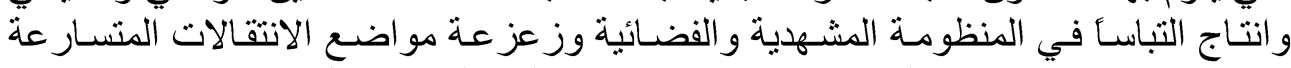

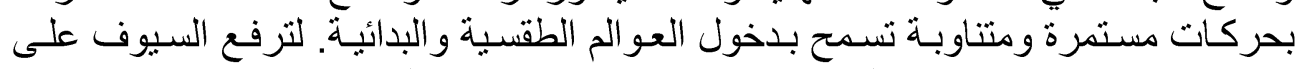

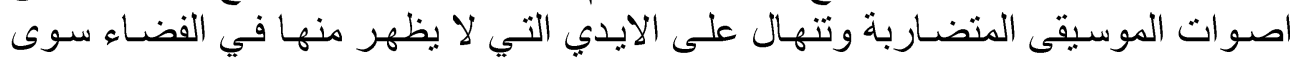

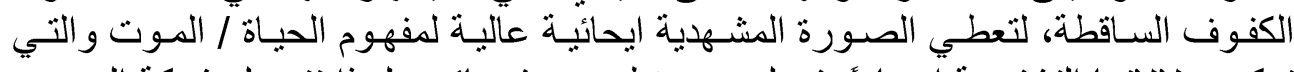

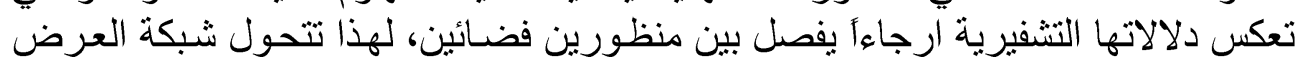

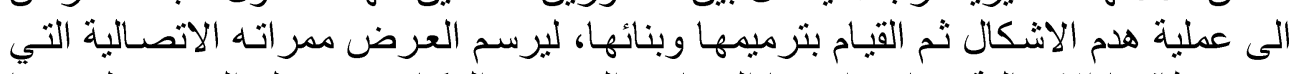

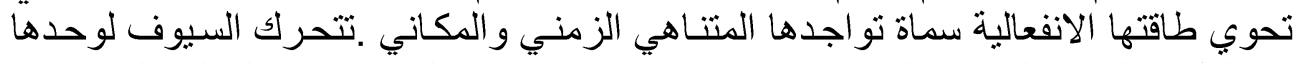

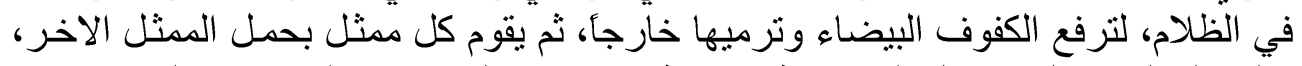

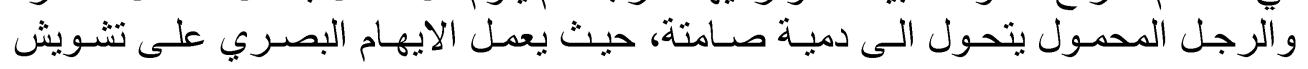

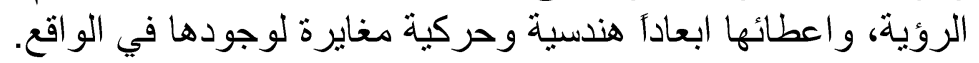

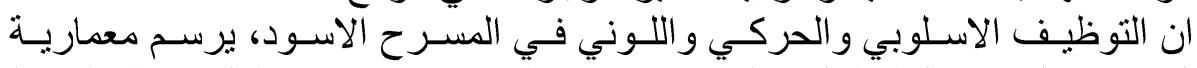

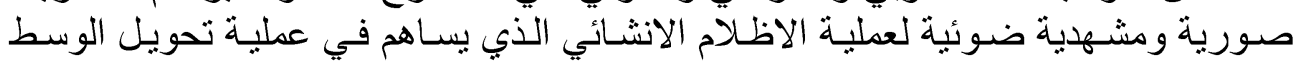

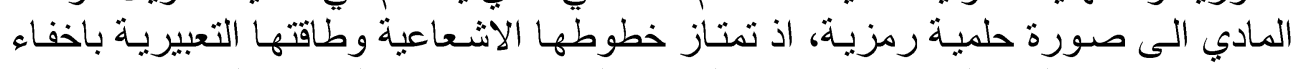

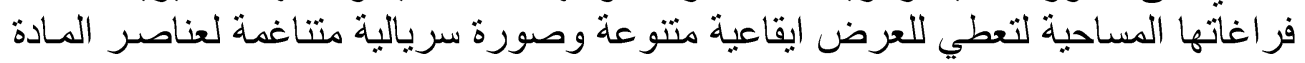

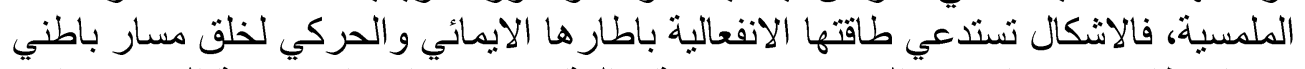

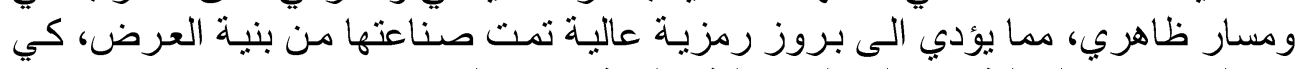

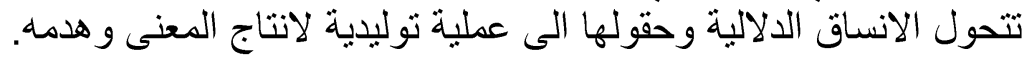

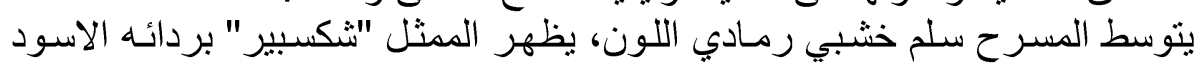

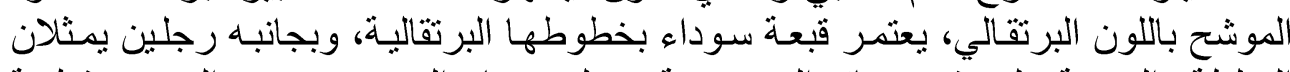

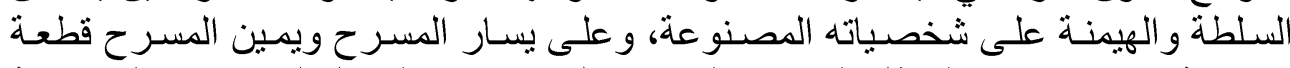

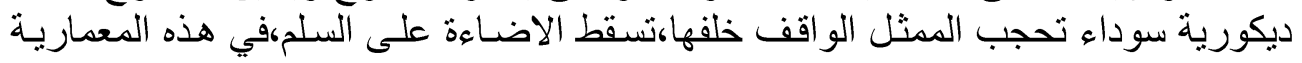

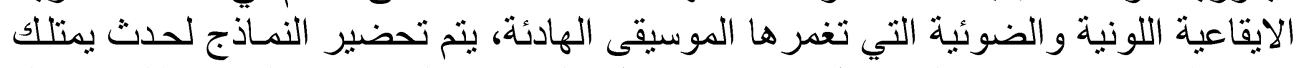

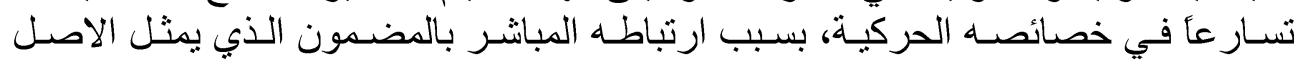

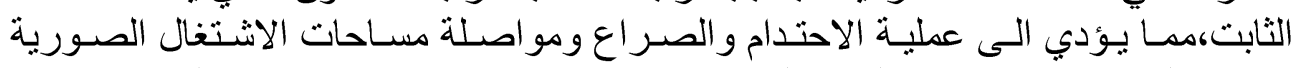

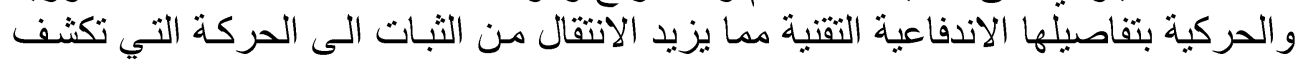

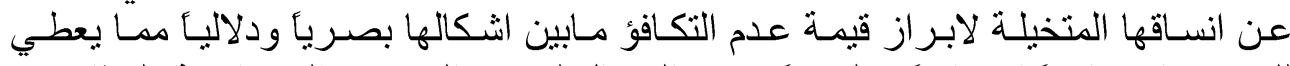

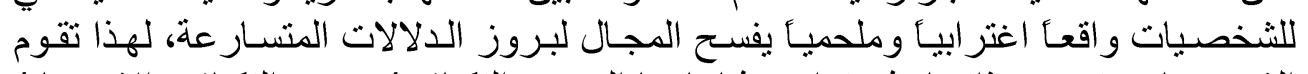

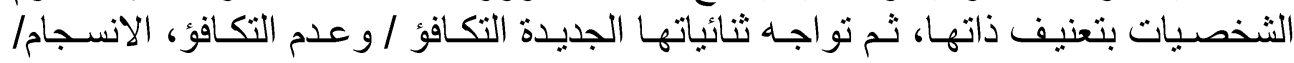

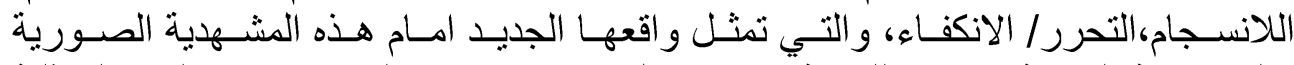

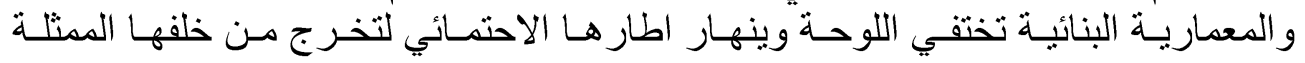

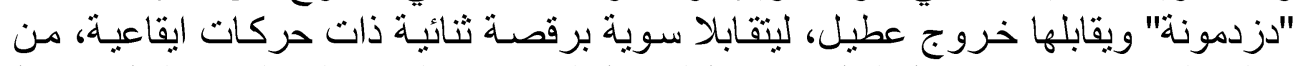

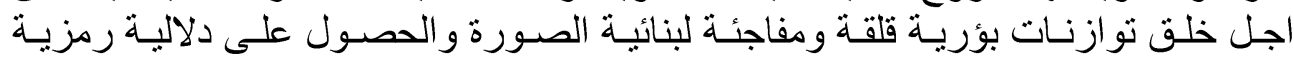


مغايرة، و الدخول في منطقة التنظيم الحركي والايقاعي الذي يبعد الاحداث عن وجهتها

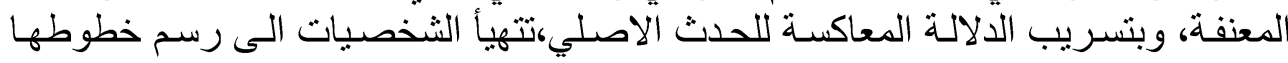

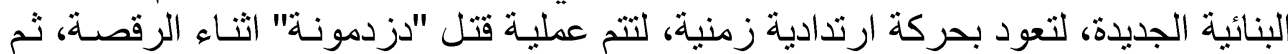

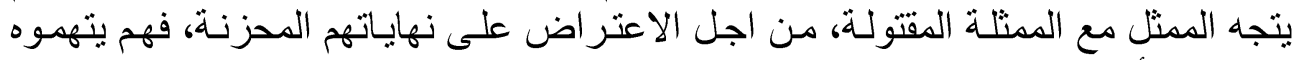

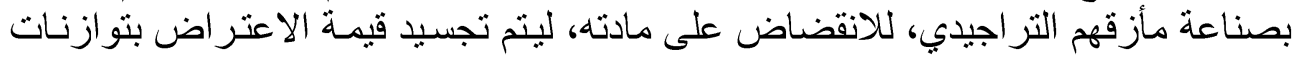

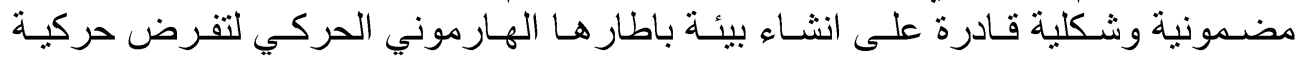

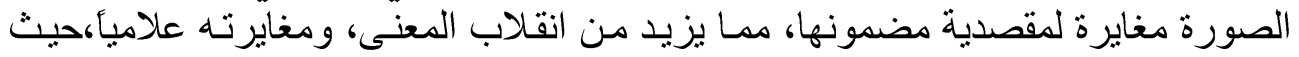

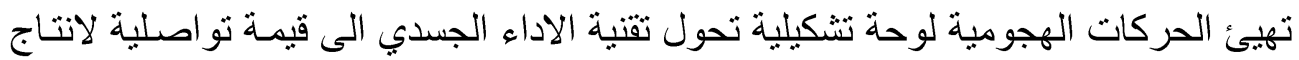

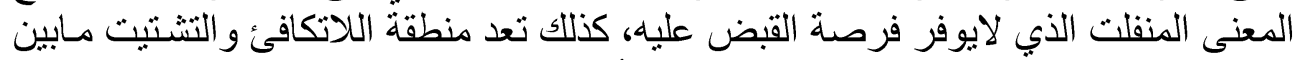

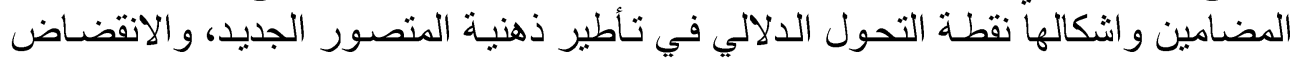

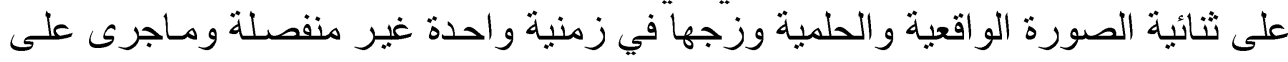

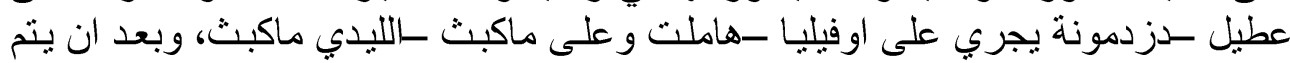

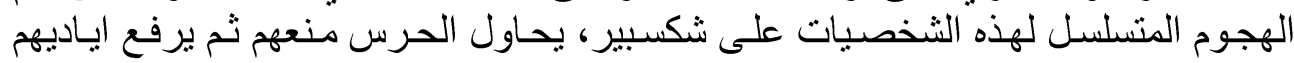

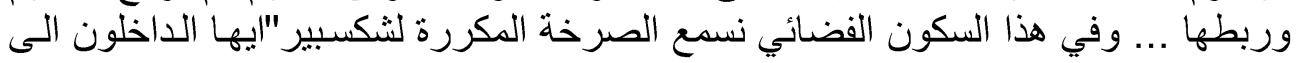

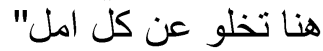

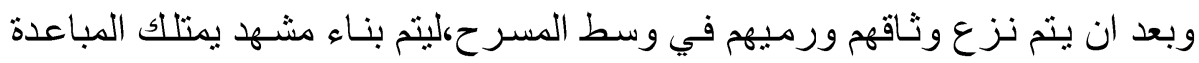

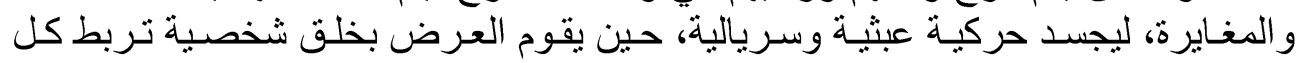

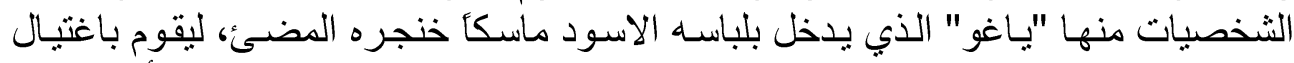

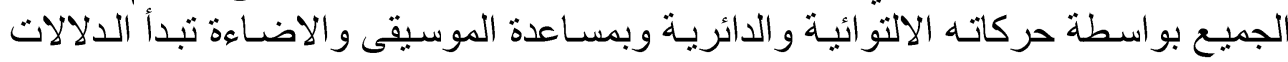

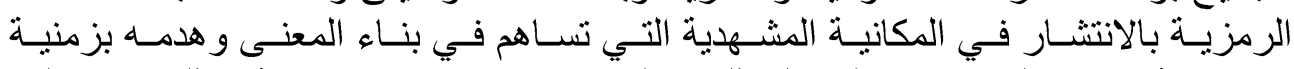

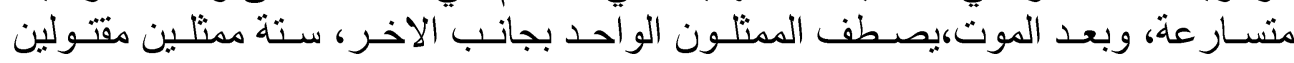

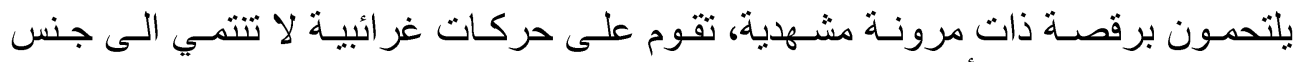

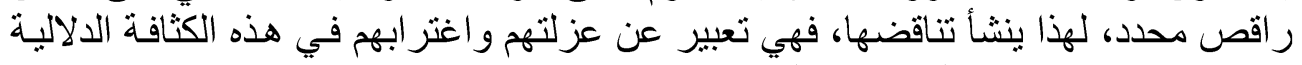

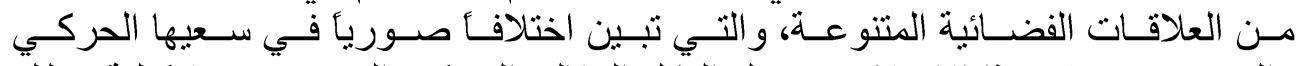

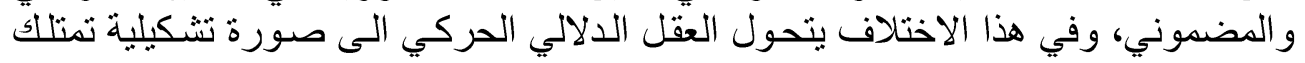

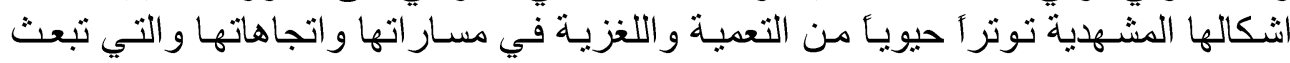

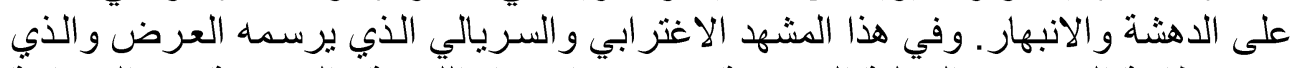

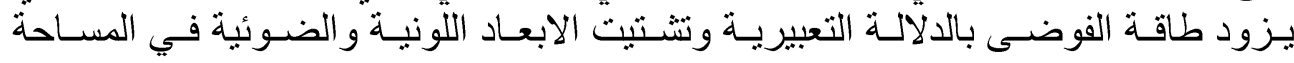

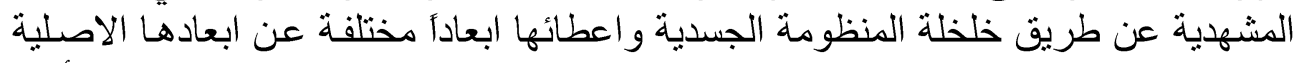

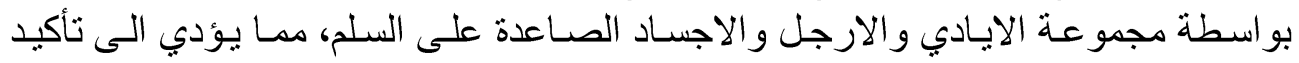

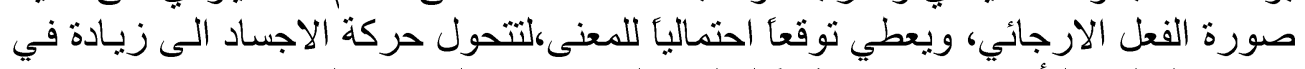

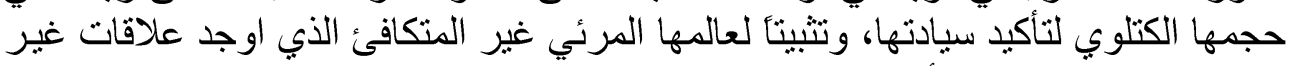

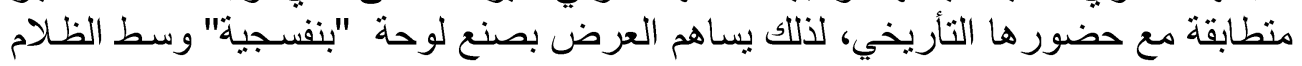

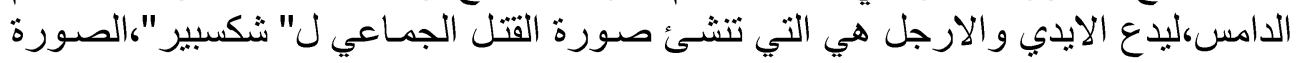

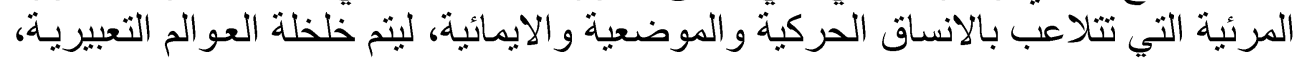

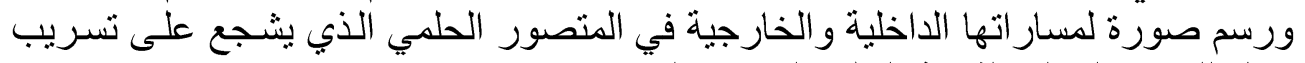
هائل للمعنى المنفلت لثنائية النظام المرئي /اللادمرئي. 


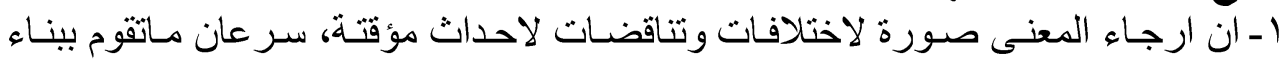

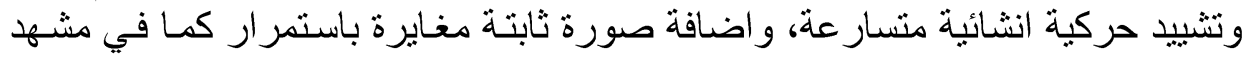
قتل (ياغو) للشخصيات.

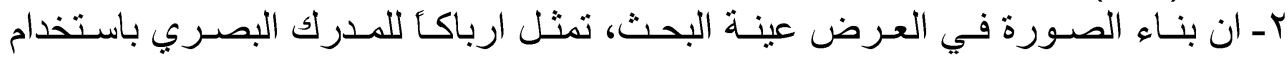

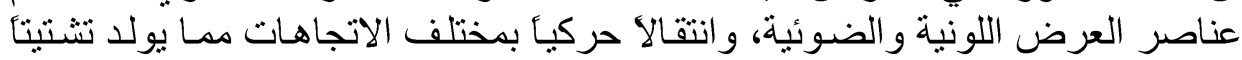

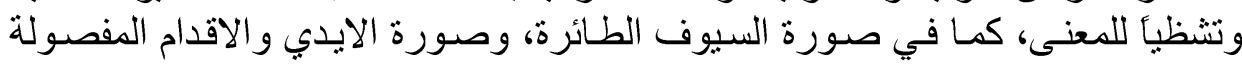

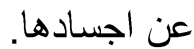

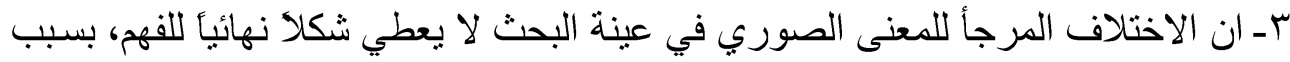

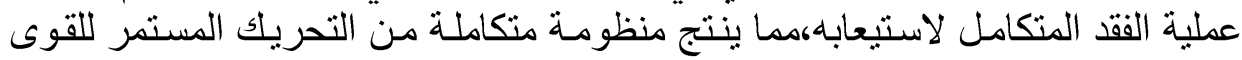

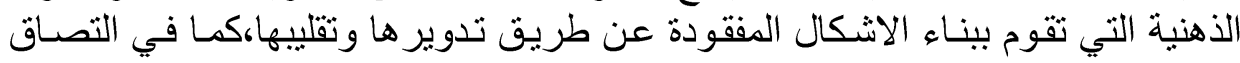

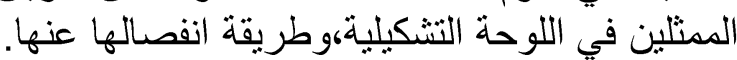

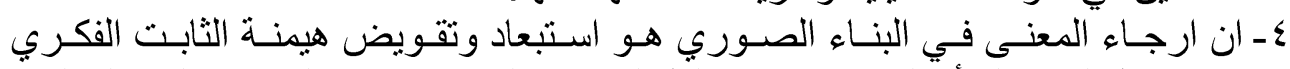

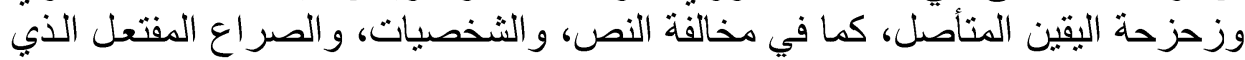
فرضته الرؤية الاخر اجية، من اجل الدخول في لعبة الدو الدان، لتحريك و استبعاد المعنى.

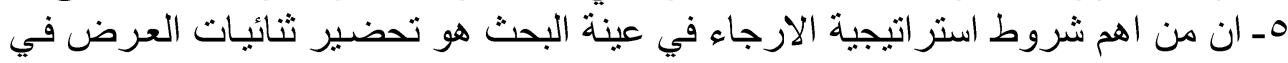

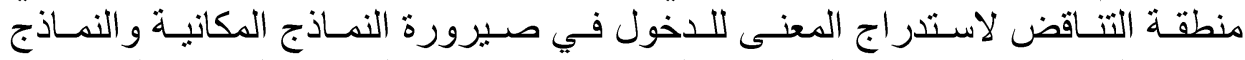

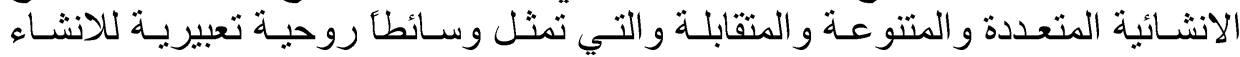

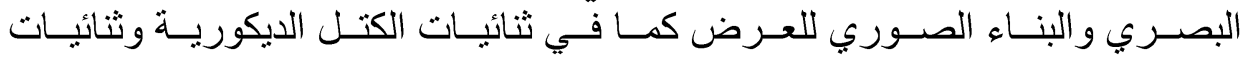

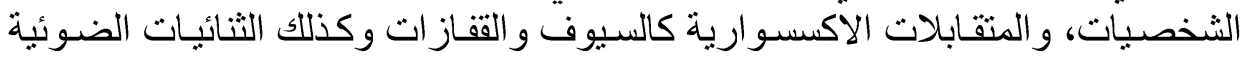
و اللونية.

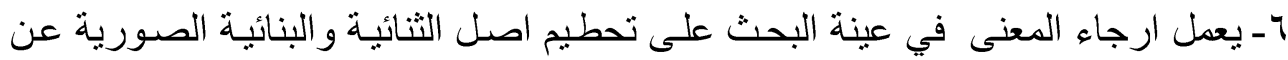

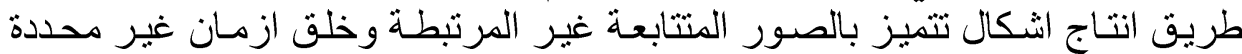

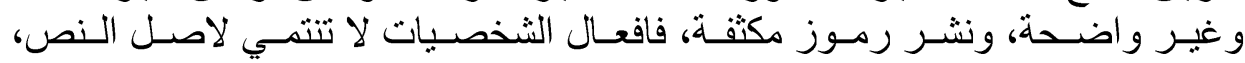

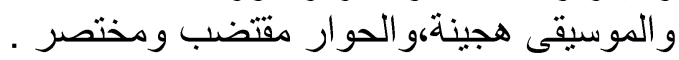
Vـ الاتجاهات الاخر اجية تعمل على التثبيت، بينما يعمل ارجاء المعنى على التهل التفتيت، حيث

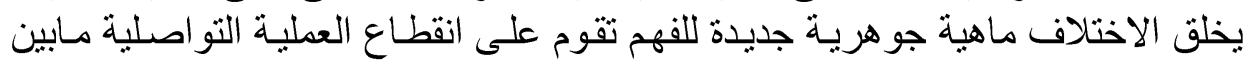

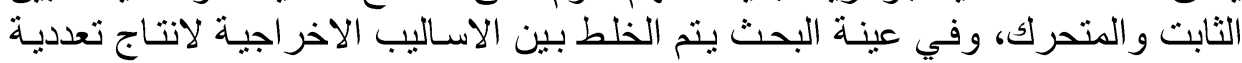

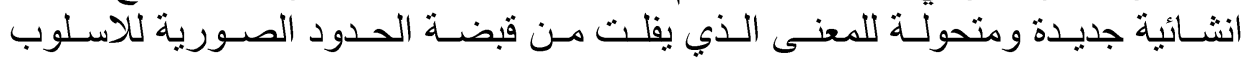

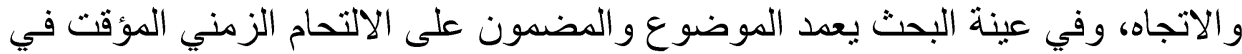

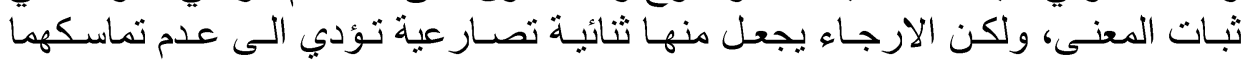

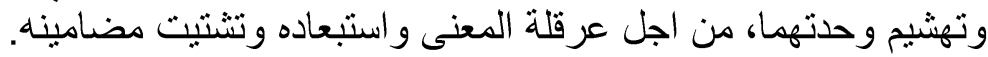




\section{Abstract \\ Delaying the meaning and building the theatrical image in the theatrical presentation Reference, mechanisms and work By Jassim Kazem Abd}

Undermining seeks to exclude the certainty constant, through the process of delaying the technical thought in order to know the limits of concepts and stable models in ideological, political and social certainty, in order to displace it, and to practice methods on its historical structure and fragmentation of its stillness, and to maintain the moving, multiple and diffuse meaning, where it becomes impossible to arrest Specific and fixed meaning. In the construction of the theatrical performance, the visual scene is subject to breaking the closed boundaries of methods and directions, subjecting the constructive process to dislocating the visual perceptor to escalate the difficulty of understanding, and not maintaining a specific meaning that meets with a spread and multiplicity in its movement and lack of control over its fixation and constipation, in the first topic, references to delay the meaning, the researcher dealt with The major movements that have affected the compensation strategy, and in the second topic, the reparative difference and the visual structure, the researcher addressed the differences and contradictions that the image is based on producing and then pouncing on it. As for the third topic, the external and external trends, the researcher dealt with some external methods, and the formal and temporary construction process. For the meaning, then the researcher established the criteria for the theoretical framework, and analyzed the research sample ( $\mathrm{Si}$ Lavie Shakespeare) by the director Russell Kazem Odeh, using the descriptive method in analyzing the research sample, and the researcher came up with some results, the most important of which is that the construction of the image in the presentation represents a confusion for the visual perception using the elements of presentation. Chromaticity and light, and a dynamic transition in various directions, which generates a dispersion and fragmentation of the meaning as in the image of swords A circle, and a picture of the hands and feet separated from their bodies, then this research was concluded with a list of sources, and a summary in English.

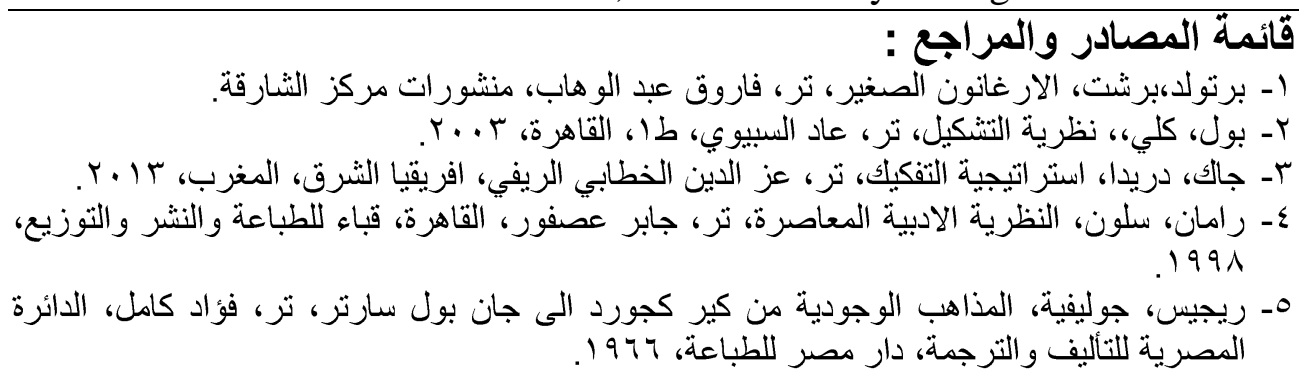


T- سعيد، علوش، معجم المصلحات الادبية المعاصرة، دار الكتاب اللبناني، بيروت، الدار البيضاء،

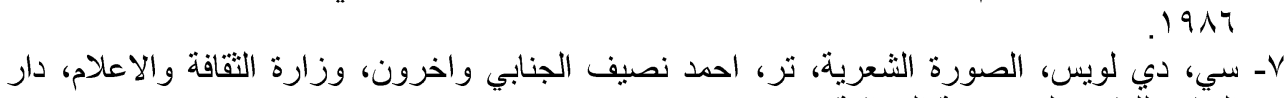

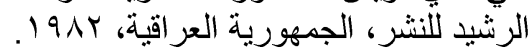

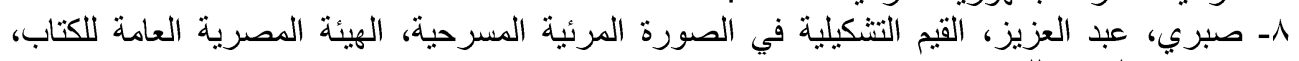

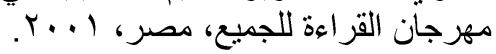
9- صلاح، فضل، النظرية البنائية في النقد الادبي، وزارة النقافة والاعلام، دار الثُؤون الثقافية العامة،

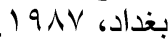
• ( - طاهر، عبد مسلم، عبقرية الصورة والمكان، التعبير التأويل النقة، دار الثنروق للنشر والتوزيع،

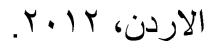

11 اـ كريستوفر، رنوريس، التفكيكية النظرية والممارسة، تر، صبري محمد حسن، الرياض، دار المريخ

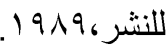

r ا ـ لويس، مليكة، الديكور المسرحي، المؤسسة المصرية العامة للتأليف والنشر، الدار المصرية للتأليف

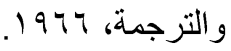

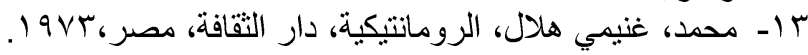

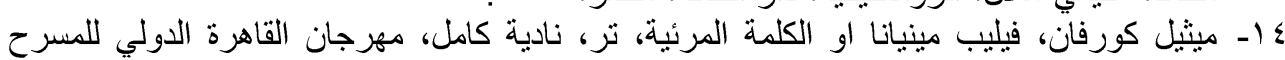

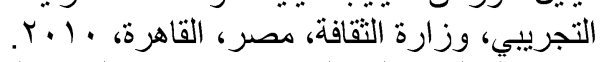

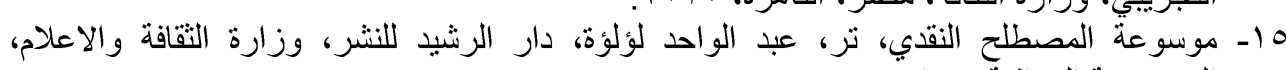

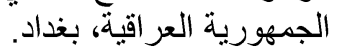

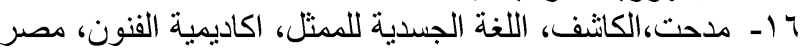

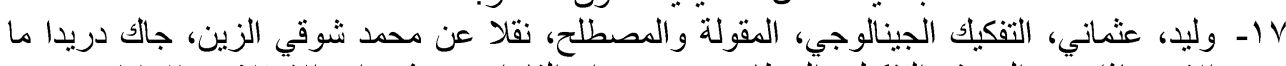

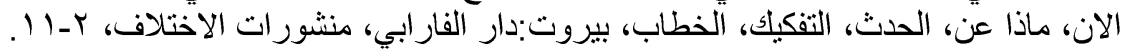

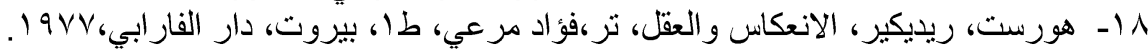

